University of Redlands

\title{
Development of a Coral Reef Mapping Tool for St. Maarten
}

A Major Individual Project submitted in partial satisfaction of the requirements

for the degree of Master of Science in Geographic Information Systems

by

James Osundwa

Ruijin Ma, Ph.D., Committee Chair

Mark Kumler, Ph.D.

December 2016 
Development of a Coral Reef Mapping Tool for St. Maarten

Copyright (C) 2016

by

James Osundwa 
The report of James Osundwa is approved.
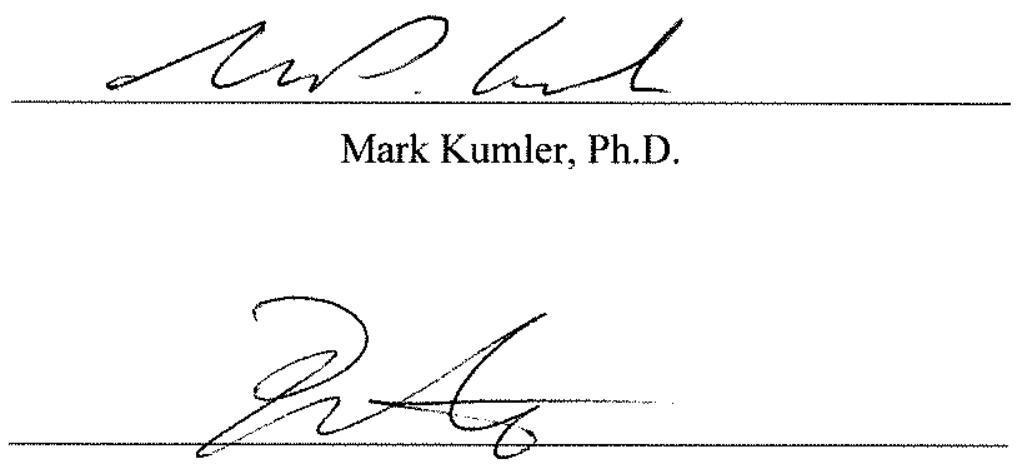

Ruijin Ma, Ph.D., Committee Chair

December 2016 



\section{Acknowledgements}

First, I would like to thank God Almighty for the wisdom, strength, peace of mind, and good health that He bestowed upon me, enabling me to complete my studies.

I would like to express my sincere gratitude to my advisor Dr. Ruijin Ma for his continuous support. His patience, motivation, and immense wisdom were invaluable to the completion of this project. I would also like to make a special acknowledgement of Prof. Mark Kumler, my second committee member for his insights and suggestions.

I am highly indebted to my family for their prayers and encouragement that helped me get through the program. My beloved and supportive wife Ciiru, made immense sacrifices, stood by my side and inspired me to complete this undertaking.

I would also like to thank Jack Dangermond, the President of Esri, and the University of Redlands MS GIS Program for funding my studies at the University. This accomplishment would not have been possible without their generous giving.

Lastly, I would like to thank my Cohort 29 colleagues and friends. Your camaraderie and encouragement helped me make it through the program. 



\author{
Abstract \\ Development of a Coral Reef Mapping Tool for St. Maarten \\ by \\ James Osundwa
}

An abstract is a self-contained, summary description of the project report. An abstract Coral reefs contribute significantly to the socio-economic well-being of the people of St. Maarten, an island in the Caribbean. These coral reefs are rapidly declining due to various environmental and social factors. This project developed a prototype citizen scientist mapping tool comprised of an Android mobile application built using a customized version of an Open Source software called Open Data Kit (ODK), and an ArcGIS Online web mapping application built using a standard template of Esri's Web AppBuilder. This tool was designed to assist recreational divers and other local stakeholders to conveniently report their observations on the status of coral reefs in their area. Users can publish these observations directly from their smartphones to a publiclyaccessible web mapping application. Such observations will contribute to the development of a Coastal Protection Master Plan for St. Maarten. The tool has the potential to provide vital information for coral reef conservation and repopulation, while at the same time creating awareness on the subject in St. Maarten. 



\section{Table of Contents}

Chapter 1 - Introduction ................................................................................................ 1

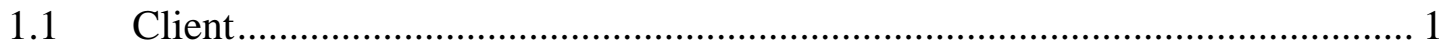

$1.2 \quad$ Problem Statement ........................................................................... 2

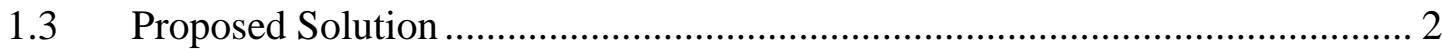

1.3.1 Goals and Objectives ........................................................................... 2

1.3.2 Scope

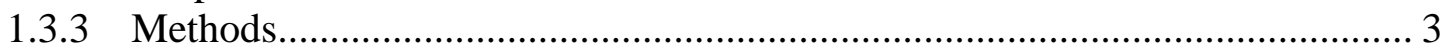

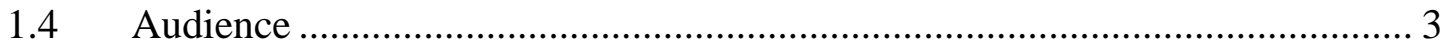

1.5 Overview of the Rest of this Report .......................................................... 4

Chapter 2 - Background and Literature Review ............................................................. 5

$2.1 \quad$ Coral Reef Mapping ................................................................................ 5

2.2 Citizen Science and Volunteered Geographic Information (VGI) .................... 6

2.3 Citizen Science in Coral Reef Mapping........................................................... 7

2.4 Mobile Mapping and Location-Based Services............................................... 7

2.5 Mobile Application Development......................................................... 8

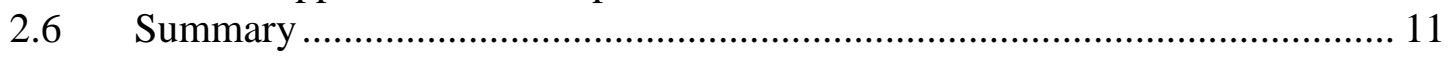

Chapter 3 - Systems Analysis and Design........................................................................ 13

$3.1 \quad$ Problem Statement ........................................................................... 13

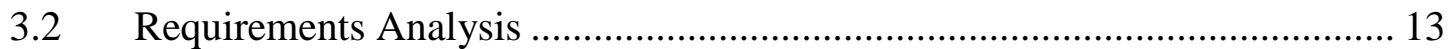

3.2.1 Functional Requirements ......................................................................... 14

3.2.2 Non-Functional Requirements ................................................................ 16

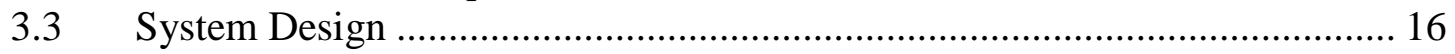

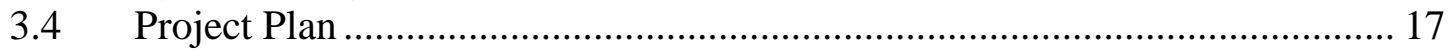

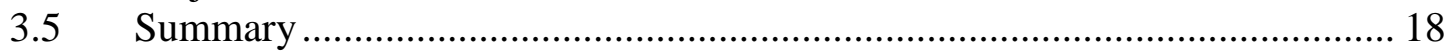

Chapter 4 - Database Design......................................................................... 19

4.1 Conceptual Data Model .................................................................... 19

4.2 Logical Data Model …………………………………………….... 20

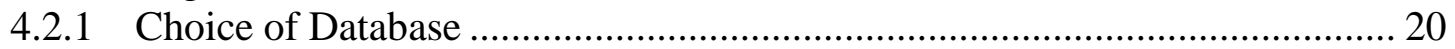

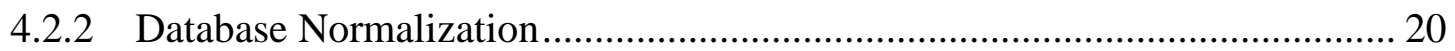

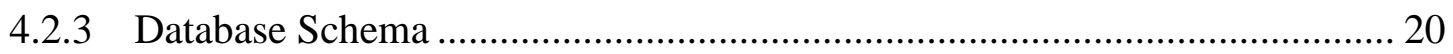

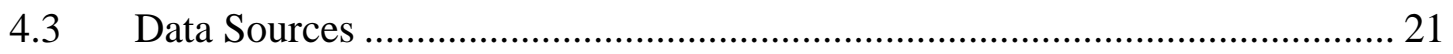

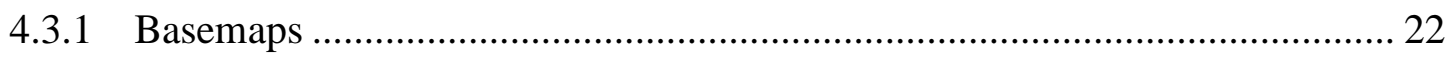

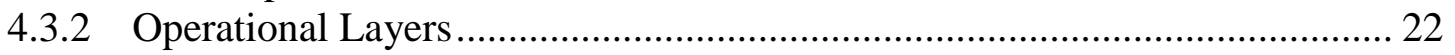

4.4 Data Scrubbing and Loading ……………………….............................. 23

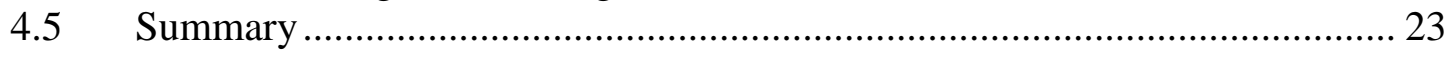

Chapter 5 - Implementation......................................................................................... 25

5.1 Mobile Application User Interface ...................................................... 25

5.1.1 User Stories and Workflows ................................................................... 25

5.1.2 User Interface Design ............................................................................. 26

5.2 Data Collection Application Development .................................................... 27

5.2.1 Setup of the Development Environment..................................................... 28

5.2.2 User Interface Design from XML............................................................. 29 
5.2.3 Mobile Application Customization .............................................................. 30

5.3 Configuration of a Cloud Storage Environment ............................................. 33

5.3.1 Web Application Datastore.......................................................................... 34

5.3.2 Web Application Deployment and Configuration ........................................... 34

5.3.3 Web Application Data Quality Control …………………………………..... 35

5.4 Web Mapping Application Development ..................................................... 37

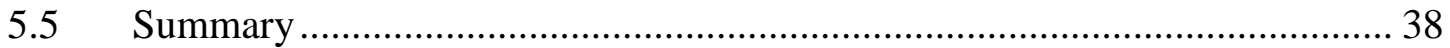

Chapter 6 - Use Cases ............................................................................................39

6.1 Use Case 1: Mobile Application …………………....................................... 39

6.2 Use Case 2: Cloud Storage Environment........................................................ 43

6.3 Use Case 3: Web Mapping Application......................................................... 45

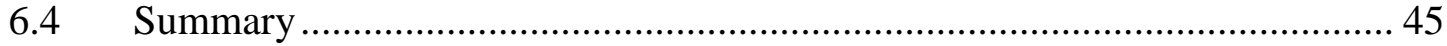

Chapter 7 - Conclusions and Future Work …....................................................... 47

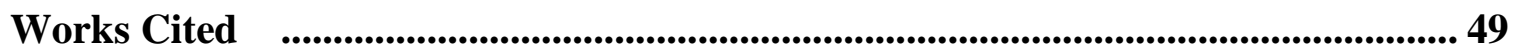

Appendix A. Mobile Application Wireframes .......................................................... 53

Appendix B. Mobile Application Activities Code ...................................................... 59 


\section{Table of Figures}

Figure 2-1: Development approaches for mobile applications .......................... 10

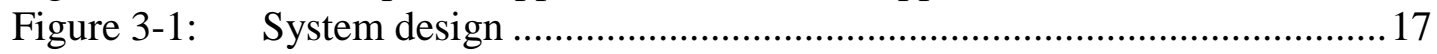

Figure 4-1: Conceptual model of project........................................................... 19

Figure 4-2: Data loading into ArcGIS Online. ...................................................23

Figure 5-1: Coral reef mapping tool user workflows. ......................................26

Figure 5-2: $\quad$ Examples of the mobile application wireframes.............................2 27

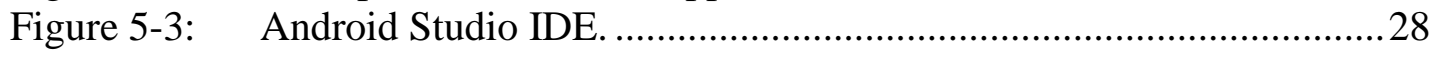

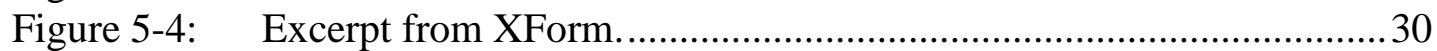

Figure 5-5: Clean-up of data submission page (before and after views)............... 31

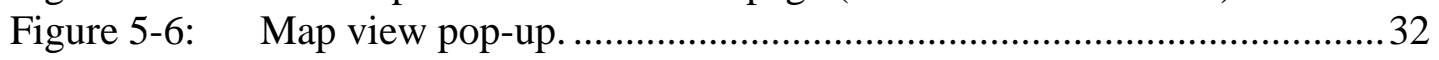

Figure 5-7: Dialog for creating a shortcut for the application. ........................... 33

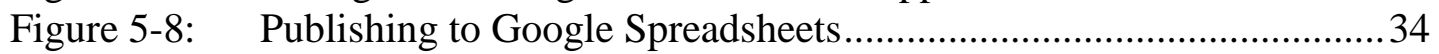

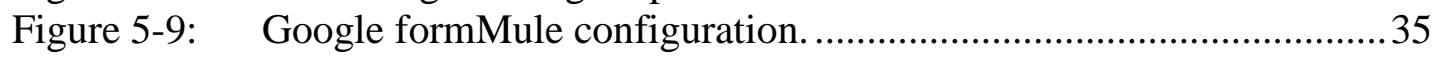

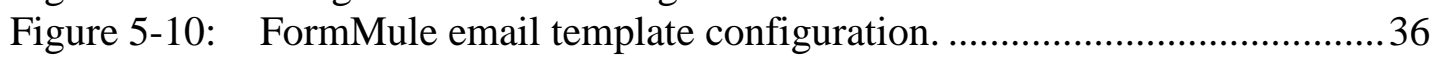

Figure 5-11: Data quality control workflow in Google Drive............................... 37

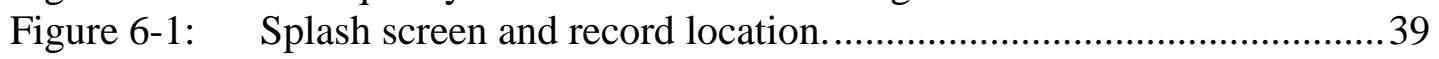

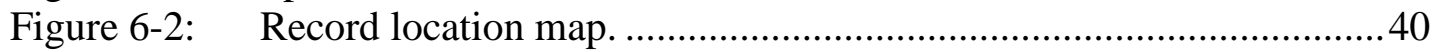

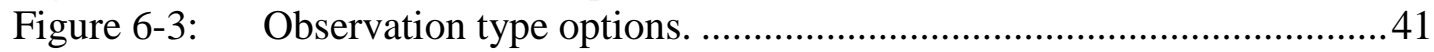

Figure 6-4: Environmental concerns and habitats observed................................42

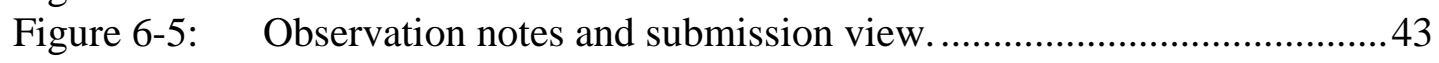

Figure 6-6: Data quality control approval form............................................... 44

Figure 6-7: Web application interface for managing data submissions................45

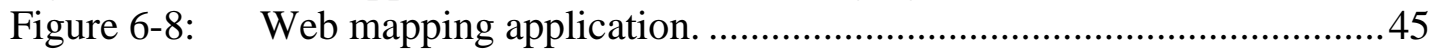





\section{List of Tables}

Table 1. Summary of mobile development approaches.......................................... 9

Table 2. Summary of mobile data collection options that were considered............... 11

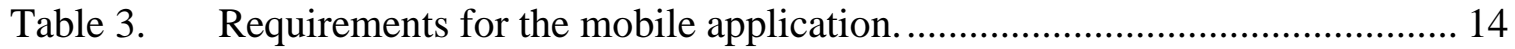

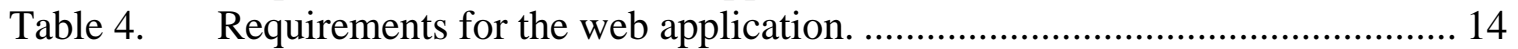

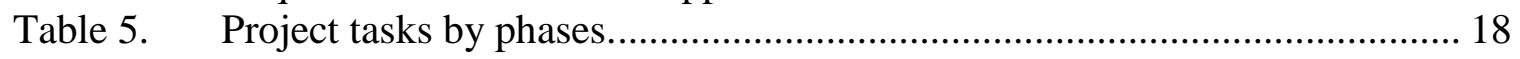

Table 6. Schema for observations dataset............................................................. 21

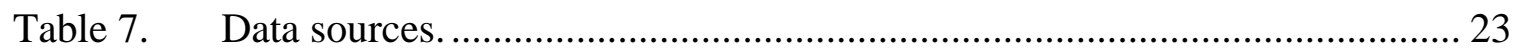

Table 8. Google App Engine free quota limits. ...................................................... 33 



\title{
List of Acronyms and Definitions
}

\author{
API Application Programming Interface \\ Esri Environmental Systems Research Institute \\ GIS Geographic Information System \\ GPS Global Positioning System \\ IDE Integrated Development Environment \\ ICRI International Coral Reef Initiative \\ NOAA National Oceanic and Atmospheric Administration \\ ODK Open Data Kit \\ OS Operating System \\ SAT Site Acceptance Testing \\ SDK Software Development Kit \\ URL Universal Resource Locator \\ VGI Volunteered Geographic Information \\ WFCRC World Federation of Coral Reef Conservation
}





\section{Chapter 1 - Introduction}

Corals are living organisms with limited development. They eat plankton, and depend heavily on algae for digestion. They secrete $\mathrm{CaCO}_{3}$ that gradually produces reef structures, commonly referred to as coral reefs. Building reefs requires large quantities of $\mathrm{CaCO}_{3}$, and not all corals can produce reefs. The formation process takes long periods of time, sometimes hundreds of years (National Oceanic and Atmospheric Administration, 2016).

Coral reefs are of great value to St. Maarten. They support numerous tourism-related businesses such as beach hotels and resorts, snorkeling, and SCUBA diving; while serving as attractions in and of themselves, these corals also provide a habitat for an entire ecosystem of marine life. Coral sand is often used in the construction industry, and to replenish eroded beaches. Hard corals on reefs serve to break large waves and protect the shoreline (Nature Foundation St. Maarten, 2007).

The Nature Foundation (2011) estimated that local marine ecosystems in St. Maarten contributed $\$ 792,000$ per year towards the economy of the island. Accordingly, St. Maarten received an average of 500,000 tourists a year (Sint Maarten Government, 2014), many of whom are interested in the marine activities. At the same time, however, the marine ecosystem is declining at an alarming rate, a situation exacerbated by Hurricane Emily, which severely damaged coral reefs across the Caribbean in 2005 (Wilkinson, Souter, \& Network, 2008).

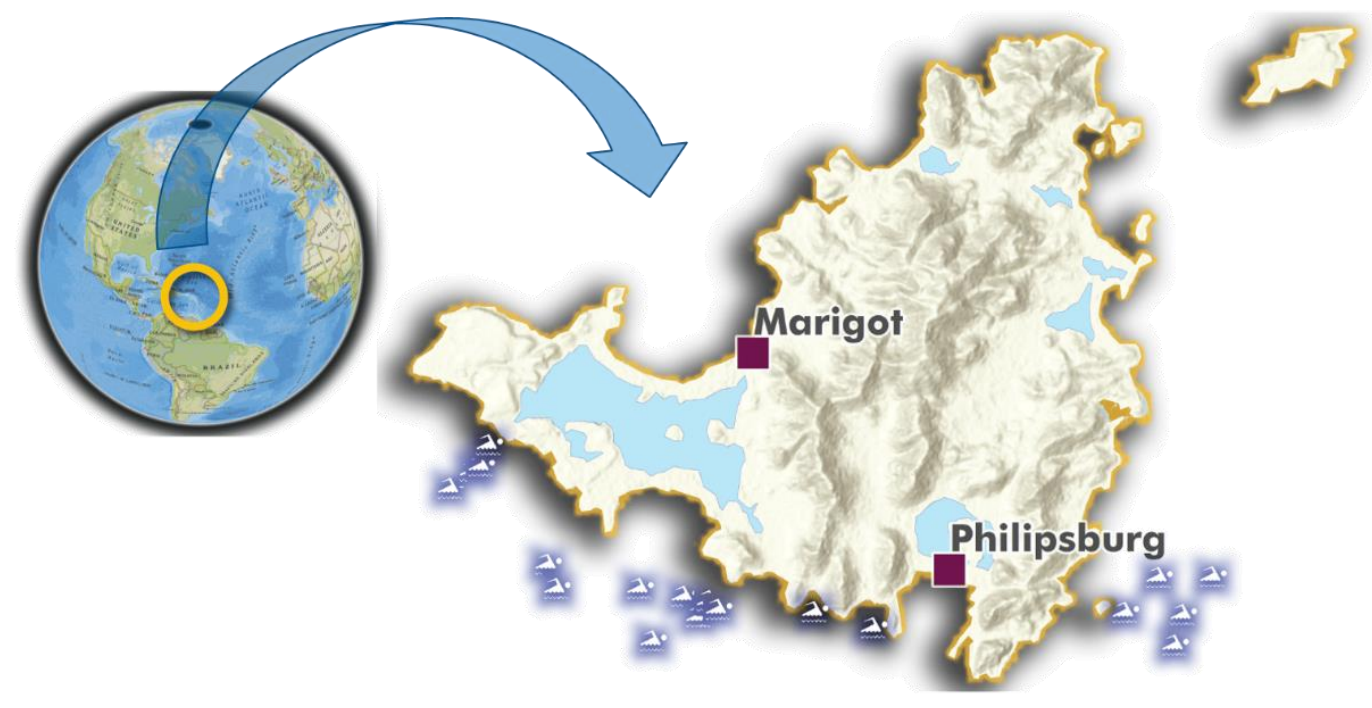

Figure 1-1: Location map of St. Maarten (SXM) Island, Caribbean.

\subsection{Client}

The client for this project was the World Federation for Coral Reef Conservation (WFCRC), a US-based 501 (c) (3) international non-profit organization headquartered in Houston, Texas. The client's mission was to collect and publish information vital to ocean's corals, strategies for mitigating threats, and connecting individuals and 
corporations who have the ability and know-how to provide support in conservation, repopulation, and disaster relief. To support these activities, WFCRC needed to engage recreational divers and the local community in providing ancillary data and information, while at the same time creating public awareness of the underlying issues.

The primary contact for this project was Vic Ferguson, the founder and Executive Director, based at the WFCRC headquarters in Houston, Texas. The client was responsible for testing and implementing the prototype of the tool in the field and using it to collect information from recreational divers and other volunteer citizen scientists. The client partnered and collaborated with other stakeholders in St. Maarten, such as The Nature Foundation of St. Maarten, and the "Save the Lagoon JellyFish Campaign."

\subsection{Problem Statement}

The challenge that the client faced was how to collect information on coral reefs in St. Maarten. The client was developing a Coastal Protection Master Plan, and required this information to inform the plan. While this information could have been gathered manually, it could be done more efficiently, leveraging on the experiences of recreational divers and conservation volunteers, namely the citizen scientists.

\subsection{Proposed Solution}

A tool was developed to enable citizen scientists to report their coral reef sitings. These were individuals and communities who were anticipated to go out of their way, mostly on a volunteer basis, to publish information to the application. The following section outlines the solution that was proposed, and its suitability for the client. It includes a discussion of project goals and objectives, scope, and methodologies used to develop the solution.

\subsubsection{Goals and Objectives}

The goal of this project was to develop a citizen scientist mapping tool that would enable recreational divers to publish and share information on the status of coral reefs in St. Maarten. The specific objectives of this project were to:

1. Enable recreational divers and local volunteers to publish updates of sitings of the various attributes relating to the state of corals in St. Maarten, using smartphones.

2. Provide vital information for maps that will feed into the Coastal Protection Master Plan being developed by the client. These maps will inform future marine conservation efforts.

3. Promote the effective sharing of information among the stakeholders of the coral reef conservation community of St. Maarten, and improve collaboration in conservation efforts.

\subsubsection{Scope}

The deliverables for this project were a citizen scientist mobile mapping tool, a web mapping application, a web-accessible database, and a web service. The mobile mapping tool was the main deliverable. It was based on a customized version of the Open Data Kit 
(ODK), an Open Source field data collection application. It is accessible to the relevant stakeholders on their smartphones as a program that they can download from the Android Play Store (for Android users). It enables them to log in and update their location on a map, and report on various parameters relating to coral reefs at their location. These observations are published to a web-accessible database that in turn displays them in a web mapping application through an ArcGIS Online webmap. The web-accessible database comprised of a CSV (comma-separated values) file that is accessible as a URL through the Google API, while the web mapping application is based on a standard template of Esri's Web AppBuilder.

The client provided input of their desired parameters and workflows for the mobile mapping tool. They also provided feedback regarding the aesthetics of the web mapping application. The client was solely responsible for the deployment and testing of the tool in the field, i.e. the Site Acceptance Testing (SAT). Lastly, the client was available at least once a month for a status update via teleconference.

\subsubsection{Methods}

The project implemented a mobile application, a web mapping application, and a cloud hosting solution comprised of a database and a web service. A Staged Development Lifecycle (SDLC) approach was used. This constituted several phases: a planning and design phase, a development phase, and a testing phase. The client provided input and feedback during each of these phases.

The mobile application was developed to run on Android versions 4.0 to 6.0. It was designed to consume an XML questionnaire, created according to the XLSForms specification, and to render it as a series of prompts. These prompts enable users to record their observations on coral reefs and their environment. It was designed to work both online and offline.

The cloud hosting solution was designed to host data published by the mobile application, and to notify the administrator of new data published. Further, it allowed the administrator to perform quality assurance and quality control (QA/QC) by reviewing published data, publishing approved data to a new database, and making this data available as a web service.

The web mapping application was designed as a custom Web AppBuilder application hosted on ArcGIS Online. It was deliberately made simple, using as few widgets and options as possible, so as to be usable by a wide range of non-GIS users. Emphasis was on displaying the coral reef data from the mobile application on an interactive map, alongside other relevant data.

\subsection{Audience}

This report is intended mainly for individuals with a basic knowledge of GIS and programming concepts. Such individuals might be interested in developing a similar system that utilizes mobile data collection in a map-based environment, and web mapping in the ArcGIS Online environment. No specific knowledge of GIS, programming, or coral reef science is assumed. 


\subsection{Overview of the Rest of this Report}

The remainder of this report describes how the project was implemented. Chapter 2 provides a literature review of citizen science in the context of coral reef mapping. Chapter 3 looks at the design of the system based on the client's requirements. Chapter 4 discusses the conceptual model and database design. Chapter 5 addresses the actual implementation of the system. Chapter 6 discusses the lessons learned in the implementation of the system, and what improvements might be made in future. Chapter 7 concludes the report by discussing the way forward for the project. 


\section{Chapter 2 - Background and Literature Review}

This chapter presents research relevant to coral reef mapping, in the context of citizen science and mobile application development. Section 2.1 discusses the broader spectrum of research that has gone into coral reef mapping. Section 2.2 provides an overview of citizen science and volunteered geographic information (VGI), and their use as GIS data collection methods. Section 2.3 discusses how citizen science is being used, specifically, in coral reef mapping. Section 2.4 addresses developments in mobile mapping and location-based services. Section 2.5 reviews several approaches to mobile application development, and makes a case for the approach used in this project. Section 2.6 concludes the chapter with a summary of the research.

\subsection{Coral Reef Mapping}

Much research has been carried out on using GIS and remote sensing for coral reef conservation. However, the greatest challenge facing coral reef conservation is that coral reefs are widely misunderstood. Owing to the vastness of the ocean, most coral reefs have not yet been mapped to meaningful levels of detail. In fact, according to Steven Miller and Michael Crosby (2012) only five percent of the world's reefs are mapped at a regional scale. There are several initiatives to map the world's corals.

The National Oceanic and Atmospheric Administration (NOAA) has a Coral Reef Ecosystem Division that prioritized the mapping of all coral reef habitats in U.S. waters to depths of at least 30 meters. It has produced accurate maps of the extent, nature, and health of the habitats. These maps help resource managers make informed decisions regarding coral reefs. (National Oceanic and Atmospheric Administration, 2015).

The International Coral Reef Initiative (ICRI) is an informal partnership between international, governmental, and non-governmental organizations keen on preserving coral reefs around the world. One of its goals is to quickly improve existing methods of coral reefs conservation. Since 2007, ICRI has actively advocated for the creation of a coral reef GIS, for every island of the Pacific Ocean (ICRI, 2013).

Another notable initiative is that of the Living Oceans Foundation. This foundation is a non-profit organization, founded by Prince Khaled bin Sultan of Saudi Arabia. The foundation is undertaking a five-year project called the Global Reef Expedition (Khaled bin Sultan Living Oceans Foundation, 2016) that seeks to survey all the reefs of the world, with emphasis on the most remote ones. The survey involves mapping and characterizing each coral reef ecosystem by status, threats, resilience to threats, habitat, and other related information. The foundation employs a combination of Hyperspectral Remote Sensing images (WorldView2) and scuba diving surveys. Since 2011, it has successfully surveyed over 20 coral reef locations, across the Atlantic, Pacific, and Indian Oceans (Lauren, 2016).

Lastly, the XL Catlin Seaview Survey is an undersea mapping project that was undertaken through a partnership between the World Resources Institute, IUCN, NOAA, and Scripps University. This project completed the surveying and mapping of Southeast Asia's Coral Triangle in 2014. This area of over 647 million hectares is thought to contain over $75 \%$ of all known coral species. It involved using specially-designed digital cameras, and taking photographs along two 40 kilometer transects. Some of the resulting 
images have since been made available through Google Maps (Gonzalez Rivero \& Hoegh-Guldberg, 2013).

\subsection{Citizen Science and Volunteered Geographic Information (VGI)}

The past decade has seen a rapid increase in public participation in GIS through web and mobile devices. Such participation is often referred to as Volunteered Geographic Information (VGI) or citizen science. VGI is a form of collaborative mapping, where the public volunteers to collect, share, maintain, and use information about geographic features (Goodchild, 2007).

A citizen scientist has been described by Jonathan Silvertown (2009) as a volunteer who collects data as part of a scientific enquiry. This volunteer usually focuses on the data collection, and does not process the data or write scientific articles. Silvertown (2009) further discusses the pros and cons of using non-scientist volunteers for scientific discovery, coming to the conclusion that citizen science has been widely accepted among professional scientists. Volunteer data collection is the context within which the terms "citizen science" and "citizen scientist" are used throughout this report.

Some examples of VGI include OpenStreetMap (OSM), Google Mapmakers, and Wikimapia, all of which attempt to create a digital map of the world. The accelerated adoption of VGI has been fueled by the worldwide proliferation of the Internet, and its increasing use for social interaction, decision-making, and education. Today, $40 \%$ of the world's population has internet connections (Internet Live Stats, 2016). Of these users, over $60 \%$ have a smartphone, a trend that is expected to continue increasing (Statistica, 2016).

Citizen Science has been used in field data collection since as early as Audubon's Christmas Bird Count in 1900. Frank Chapman, an ornithologist, recruited 27 volunteers to count birds, rather than shooting them in the holiday season (Connors, Lei, \& Kelly, 2012). It has since grown to over 70,000 volunteer citizen scientists in over 20 countries.

Arguably one of the most successful crowdsourcing, map-based tools that has been developed is Ushahidi. This is an open-source project that allows users to crowdsource crisis information via mobile devices. It boasts a 20 million population reach, since its inception in January of 2008 (Okolloh, 2009).

King (2012) developed a mobile mapping tool for managing marine mammal observations in Southern California. The tool was intended to help Dr. Lei Lani Stelle of the University of Redlands to collect and manage these observations, using the volunteered geographic information (VGI) approach. It enabled her to save time and resources. The solution involved the development of an Android application, a web mapping application, and a geodatabase for storing data collected through the VGI process.

Sim (2015) developed a mobile application to support inventory management during emergency incidents such as wildfires. The tool was developed for iOS, and allowed the field staff of Abel Fire Equipment to scan QR codes on equipment during deployment, thus improving the management of the same. The tool helped to reduce the cost of locating and/or restocking lost equipment upon completion of emergency operations. It reduced human error and inefficiencies in capturing and communicating information across the organization. 


\subsection{Citizen Science in Coral Reef Mapping}

Little development has been done in terms of a citizen science tools to support coral reef mapping, despite there being many volunteer-based organizations in the coral reef domain. One organization that has developed a citizen science tool for coral reef mapping is Reef Check, a non-profit that focuses on training recreational divers as citizen scientists, and using them to monitor and report on the health of the reefs (2016, December 12). Using this strategy they have surveyed over 10,000 locations in over 90 countries (Reef Check Foundation, 2014). Using citizen scientists, they were able to survey the entire coast of Haiti, and discover new coral reefs that went undetected in previous researches (Reef Check Foundation, 2014).

Another such initiative is the Eyes on the Reef Project. This is a volunteer-based organization that was formed to enable citizen scientists to monitor and report on coral bleaching in Hawai' $i$, mainly to combat the spread of a coral disease called Crown-OfThorn Sea Star (2016, October 10). A web-based citizen science tool was developed to enable the general public to report their observations of coral reefs on the organization's website. Resource managers were able to detect and respond to coral reef threats quickly and effectively, over large areas that they would otherwise not have been able to cover easily. The involvement of citizen scientists also served an important role in sensitizing and educating the local communities as to the issues affecting coral reefs.

It should be noted that neither of these tools are mobile; both function as web-based tools. This is due primarily to a lack of funding to develop such an application. No citizen science mobile mapping tool for coral reefs was identified in this research.

\subsection{Mobile Mapping and Location-Based Services}

Mobile computing is arguably the most dynamic and innovation-driven field of technology today. Despite this, it still has a huge potential for growth, especially in areas that industry experts term as emerging markets. The resulting trend has been an increasing participation by the public in Location-Based Services (LBS), both as producers and consumers.

Some mobile applications where the public act as consumers of LBS include Foursquare, Yelp, Gowalla, Loopt, Google Latitude, Buzzd, and GyPSii. These applications are based on geofencing, a term used to refer to determining a geographical extent based on a user's location. Further, they determine what goods and services are found at this location, what the user likes, and what is popular, based mainly on crowdsourced data such as reviews. Contributors get incentives such as discounted services (SocialCompare, 2015).

A more recent example of consumer LBS is the Pokémon Go mobile game, by Niantic, that went viral in June 2016 ( 2016, October 11). This game is based on LBS and augmented reality. Players use their smartphone GPS and camera to capture, battle, and train virtual creatures called Pokémon, located in real-life geographic locations. Most users have no idea that the game is driven by GIS and LBS. 


\subsection{Mobile Application Development}

There are three main approaches to mobile GIS application development: web-based, native-based, and hybrid-based. The web-based approach relies on the user accessing the application from within a mobile web browser. This benefits from recent advances to support feature-rich and standards-compliant web browsers, such as Chrome Firefox, and Safari. Such browsers support HTML5, JavaScript (JS), Cascading Style Sheets (CSS), and offline storage and caching. The resulting applications are rich in functionality and performance, providing a user experience similar to the native applications. These applications are considered responsive, i.e. they adapt their layout to different device sizes. Further, these applications are truly cross-platform.

The native-based approach tailors applications to target a specific operating system, such as Android, iOS, and Windows. These applications must be downloaded and installed on the user's mobile device. Native applications provide the fastest performance and most access to the built-in capabilities of the mobile device, such as camera, microphone, calendar, and GPS. Native applications can be discovered more easily through their respective app stores. Each operating system application is built using a different software development kit (SDK) and programming language. For example, iOS uses the Objective $\mathrm{C}$ language in the iOS SDK; Android uses Java language in the Android SDK; and Windows phone uses .NET in the Windows Phone SDK.

The hybrid-based approach takes web applications built in HTML5 and packages them in a native application shell. The resulting applications are built on platformindependent technologies (HTML5, JS, CSS). They follow a model of build once, and deploy to many different app stores. Examples of platforms used to build these applications are Apache Cordova, Adobe PhoneGap, Appcelerator Titanium Studio, Microsoft's Xamarin based on C\#, and more recently Esri's AppStudio for ArcGIS based on Quartz/Qt and C++/QML. 
Table 1. Summary of mobile development approaches (Korf \& Oksman, 2016).

\begin{tabular}{|l|l|l|l|}
\hline & Native & HTML5 & Hybrid \\
\hline $\begin{array}{l}\text { Application } \\
\text { Features }\end{array}$ & \multicolumn{2}{|l|}{} \\
\hline Graphics & Native APIs & HTML, Canvas, SVG & HTML, Canvas, SVG \\
\hline Performance & Fast & Slow & Slow \\
\hline $\begin{array}{l}\text { Native look and } \\
\text { feel }\end{array}$ & Native & Emulated & Emulated \\
\hline Distribution & Appstore & Web & Appstore \\
\hline Device Access & \multicolumn{2}{|l|}{} \\
\hline Camera & Yes & No & Yes \\
\hline Notifications & Yes & No & Yes \\
\hline Contacts, calendar & Yes & No & Yes \\
\hline $\begin{array}{l}\text { Offline storage } \\
\text { Secure file } \\
\text { storage }\end{array}$ & Shared SQL & $\begin{array}{l}\text { Secure file system, shared } \\
\text { SQL }\end{array}$ \\
\hline Geolocation & Yes & Yes \\
\hline Gestures & \multicolumn{2}{|l|}{} \\
\hline Swipe & Yes & Yes \\
\hline Pinch, spread & Yes & No & Yes \\
\hline Connectivity & $\begin{array}{l}\text { Online and } \\
\text { offline }\end{array}$ & Mostly online & Online and offline \\
\hline $\begin{array}{l}\text { Development } \\
\text { skills }\end{array}$ & ObjectiveC, Java & $\begin{array}{l}\text { HTML5, CSS, } \\
\text { Javascript }\end{array}$ & HTML5, CSS, Javascript \\
\hline
\end{tabular}

The choice of platform is dependent on various factors such as the developer's skillset, functionality requirements, the targeted platform, and the availability of funding (Figure 2-1). 


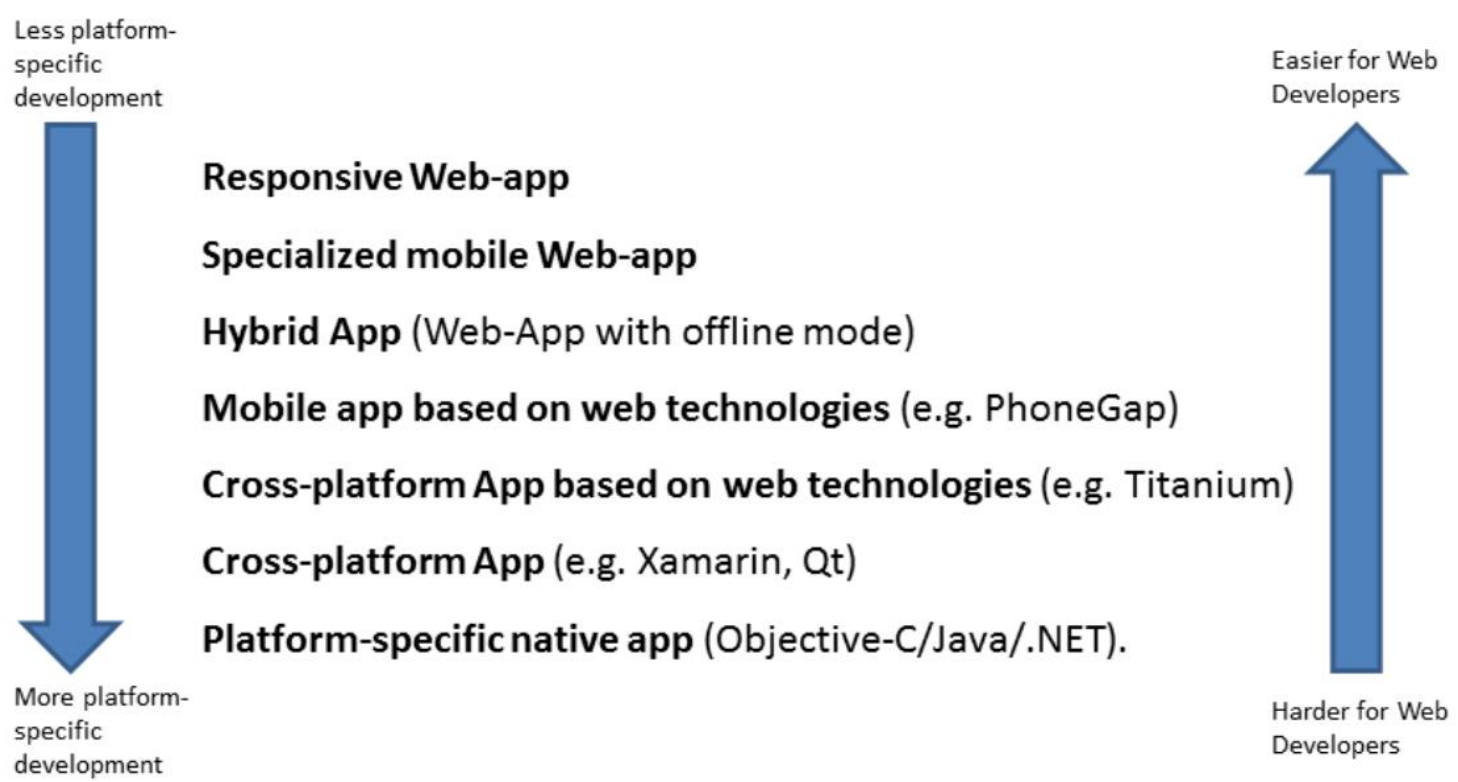

Figure 2-1: Development approaches for mobile applications (Müller, Medyckyjscott, Cowie, Heuer, \& Roudier, 2013).

Looking at mobile application development strategies in the context of mobile GIS, web-based applications can be developed using the various existing web mapping libraries. The main ones are Esri, Google Maps, OpenLayers, Leaflet, and Yahoo, which were developed using JavaScript. For developing native apps, Esri has developed ArcGIS Runtime SDKs for Android, iOS, and Windows Phone.

For mobile data collection, Esri developed several solutions including: Survey123 for ArcGIS, Collector for ArcGIS, and GeoForm. Further, Esri has developed a platform called AppStudio for ArcGIS that allows a developer to customize an application, based on an existing template, and deploy it to various platforms (iOS, Android, Windows, Mac, and Linux).

Survey123 is a form-centric data collection application; its focus is on providing a data collection form, with less emphasis on geographic locations, even though the latter are also collected. Collector for ArcGIS is a map-centric data collection application; it is focused on the map, and data collection is done directly within the map interface. It also supports collection of more advanced geometry types. GeoForm is a browser-based data collection application that is form-centric (Chivite, 2015).

Open Data Kit (ODK) is a collection of open-source tools for developing mobile data collection solutions. These tools were developed by the University of Washington's Department of Computer Science and Engineering. They are form-centric, and are based on the XLSForms, a standard for authoring data collection forms in Microsoft Excel. 
Table 2. Summary of mobile data collection options that were considered.

\begin{tabular}{|l|l|l|l|l|}
\hline & Survey123 for ArcGIS & Collector for & GeoForm & Open Data Kit \\
\hline Data collection style & Form Centric & Map Centric & Form Centric & Form Centric \\
\hline Supports capturing new & Yes & Yes & Yes & Yes \\
\hline Supports editing existing & No (Planned early 2017) & Yes & No & No \\
\hline Smart forms & Yes (XLSForms) & No & No & Yes (XLSForms) \\
\hline Works offline & Yes & Yes & Yes & Yes \\
\hline $\begin{array}{l}\text { Supports anonymous } \\
\text { access }\end{array}$ & $\begin{array}{l}\text { No (Planned before end } \\
\text { of 2016) }\end{array}$ & No & Yes & No \\
\hline Platforms & iOS, Android, Windows, \\
Mac, Linux & $\begin{array}{l}\text { iOS, Android, } \\
\text { Windows }\end{array}$ & Web & Android \\
\hline Technical Support & Esri \& Community & $\begin{array}{l}\text { Esri \& } \\
\text { Community }\end{array}$ & $\begin{array}{l}\text { Esri \& } \\
\text { Community }\end{array}$ & ODK \& Community \\
\hline
\end{tabular}

\subsection{Summary}

Much research has been carried out on the use of using GIS and remote sensing, with most researchers focusing on using the latter to identify corals and benthic habitats (Seoane, 2012). Benthic habitats are habitats at the bottom of the ocean. Some notable work has gone into mapping several coral reef locations, such as the aforementioned Coral Triangle Project. There have even been initiatives engaging citizen scientists in coral reef mapping. However, despite the common agreement on the need for a mobile citizen science tool for coral reef mapping, no such work has been undertaken. It is in this context that this project was developed. 



\section{Chapter 3 - Systems Analysis and Design}

This chapter analyzes the client's requirements, and discusses the system design of a proposed solution; this is done in a project management context. The requirements are categorized into functional and non-functional requirements.

Section 3.1 restates the client's problem. Section 3.2 discusses the functional and non-functional requirements used in the system design. Section 3.3 discusses this system architecture design, how it met the requirements of the client, and how it aligned to each of the project deliverables. Section 3.4 discusses how this system was implemented, and what different processes were undertaken in the system design, development, and deployment. Section 3.5 gives a summary of the chapter.

\subsection{Problem Statement}

The challenge that the client the World Federation for Coral Reef Conservation faced was how to collect data and information on coral reefs, their habitats, and their environmental threats in a convenient and efficient manner. In order to reduce the cost and effort of data collection, while leveraging help from volunteer citizen scientists, the client decided to adopt an approach of using a mobile application.

\subsection{Requirements Analysis}

Functional requirements describe what functionalities the system will provide to its end users; these include what operations the user will be able to do and what information the user will be able to obtain from the system. Non-functional requirements refer to the technical and operational performance requirements of the system; these include the technology that the client will need to access, run, and maintain the system.

The deliverables for this project are a citizen science mobile mapping tool, a web mapping application, and a web service. Looking at these in terms of requirements, the citizen science mobile mapping tool and the web mapping application are the deliverables that define a solution to the client's problem, while the latter two simply support this solution in the backend. These deliverables will measure the client's satisfaction with the solution.

The following requirements were developed based on discussions with the client, research, and assumptions regarding coral reef conservation. They include functional requirements that described what capabilities the system would have, followed by nonfunctional requirements that focused on how well the system would perform. Table 3 summarizes the requirements of the mobile application, while Table 4 summarizes the requirements of the web application. 
Table 3. Requirements for the mobile application.

\begin{tabular}{|l|l|}
\hline Functional Requirements & Non-Functional Requirements \\
\hline $\begin{array}{l}\text { The mobile application will provide a form } \\
\text { to enable the user to input their observations. }\end{array}$ & $\begin{array}{l}\text { The mobile application will require a user to } \\
\text { install it as an Android Application Package } \\
\text { (APK). }\end{array}$ \\
$\begin{array}{l}\text { The mobile application will allow the user to } \\
\text { record their location using the device's } \\
\text { inbuilt GPS. }\end{array}$ & $\begin{array}{l}\text { The mobile application will run on the } \\
\text { Android operating system, versions } 4.0-6.0 .\end{array}$ \\
$\begin{array}{l}\text { The mobile application will allow a user to } \\
\text { record observations while offline, and will } \\
\text { upload them when the user connects to the } \\
\text { internet. }\end{array}$ & $\begin{array}{l}\text { The mobile application will allow a user to } \\
\text { navigate to their current location, and select a } \\
\text { location by clicking on the map }\end{array}$ \\
$\begin{array}{l}\text { The mobile application will allow a user to } \\
\text { capture and upload a photograph of a feature, } \\
\text { using the device's inbuilt camera. }\end{array}$ & \\
$\begin{array}{l}\text { The web application will display an } \\
\text { OpenStreetMap basemap, zoomed to St. } \\
\begin{array}{l}\text { Maarten, and displaying coral reef } \\
\text { observations, upon launching. }\end{array}\end{array}$ & \\
\hline
\end{tabular}

Table 4. Requirements for the web application.

\begin{tabular}{|l|l|}
\hline Functional Requirements & Non-Functional Requirements \\
\hline $\begin{array}{l}\text { The web application will support basic } \\
\text { navigation: zoom in/out and panning/move. }\end{array}$ & $\begin{array}{l}\text { The web application will be accessible } \\
\text { through Google Chrome 28, Internet } \\
\text { Explorer 9, Mozilla Firefox 22, and Safari } 9\end{array}$ \\
$\begin{array}{l}\text { The web application will support toggling of } \\
\text { layers on/off, and switching between } \\
\text { basemaps. }\end{array}$ & $\begin{array}{l}\text { The web application will be hosted in the } \\
\text { client's ArcGIS Online account, and be } \\
\text { embedded in the client's website }\end{array}$ \\
$\begin{array}{l}\text { The web application will support information } \\
\text { templates / pop-up windows when clicked by } \\
\text { the user. }\end{array}$ & \\
\hline
\end{tabular}

\subsubsection{Functional Requirements}

The first functional requirement was that the mobile application will require a user to download and install an Android Application Package (APK) from the client's website; this may require the user to enable an Android security setting to allow installation of 
apps from unknown sources. Any public user with an Android smartphone with Android operating system versions 4.0 to 6.0 can download the application and install it on their phone. While not explicitly guaranteed, the application may run on older versions of Android. However, it will not support installation on Windows or Apple devices.

The second functional requirement was that the application will allow user input of the following coral reef observations into the form that opens when the mobile mapping application is launched:

1. Name of citizen scientist, to be entered by typing into a dialogue box supporting a maximum of 70 characters.

2. Coral reef siting: species and condition (healthy, bleached, damaged, or diseased), to be selected based on options provided in a dropdown menu allowing a single selection only.

3. Supporting habitat siting (mangroves, seagrass, salt ponds, algae), to be selected from a checkbox menu allowing multiple selections.

4. Human development (dredging, construction, other development projects in the vicinity), to be optionally selected from a checkbox menu allowing the user to select all that apply.

The third functional requirement was that the mobile application will enable the user to record their current location, to be automatically populated to the form by clicking the "Record Location" button in the phone. This will be based on the mobile device's GPS, or on the mobile carrier's IP address if GPS is unavailable. This information may also come from a WiFi network that the user is connecting from, if the other two options are unavailable.

The fourth functional requirement was that the mobile application will allow a user to capture and/or upload a photograph of a feature, to be optionally entered by launching the camera when the user clicks on "Upload Photograph."

The fifth functional requirement was that the web mapping application will display an OpenStreetMap basemap, zoomed to St. Maarten Island, with displayed locations of Coral Reef observations, as captured by recreational divers through the mobile mapping tool.

The sixth functional requirement was that the web mapping application will allow any internet user (without logging in) to study and understand the status of coral reefs in St. Maarten, by providing the following capabilities:

1. Toggle Layers On/Off - the application will contain the following layers that a user will be able to toggle on/off: Marine Protected Areas (MPAs), water quality, Sea Surface Temperature (SST), and benthic habitats. These layers will cover St. Maarten and its environs. They will initially be turned off when the application is launched. The user will click (or touch if using a touch-aware device) to turn a layer on, and will be able to turn on more than one layer at a time. This will enable the user to compare geographic patterns between coral reefs and other variables, and to better understand the spatial relationships.

2. Information Template / Pop-up Window - when a user clicks on a coral reef location point feature on the map, a pop-up window will be activated that will provide more details on the selected feature. Information displayed in this window is the information that was captured at this location with the mobile mapping application. 
3. Zoom In/Out - the application will zoom in/out, whenever zoom in/out button is clicked or by using finger gestures (pinching) at the desired location.

4. Pan/Move - the application will enable the user to move the map, using mouse or finger gestures.

5. Switch Basemap - the application will change the basemap to the one selected from Switch Basemap menu, from a selection of the standard 12 basemaps provided with the map.

\subsubsection{Non-Functional Requirements}

Non-functional requirements are the technologies required to build the system. They are therefore based on the technical requirements of the system. Both the mobile mapping and the web mapping application needed to be usable by people with no GIS experience. This was achieved by using streamlined interfaces, such as the simple data collection form for the mobile application, and the simple and attractive web mapping application. The latter deliberately avoided complex analysis options, or many widgets that might be confusing to the novice user, leaving only the option to navigate and toggle the maps.

The web application needed to support web browser access and be accessible through Google Chrome 28, Internet Explorer 9, Mozilla Firefox 22, and Safari 9 through a web URL. It therefore needed to be responsive and accessible via any device with these browsers, i.e. touch-aware smartphones and tablets, and personal computers. The web mapping application needed to be hosted in the client's ArcGIS Online account, and to be embedded and accessible in the client's website (http://www.wfcrc.org) or directly through the URL as provided by the client.

The mobile application needed to be developed for the Android operating system, version 4.0 - 7.0. It shall be developed in the Android Studio Integrated Development Environment (IDE), utilizing the Android Software Development Kit (SDK), or in any other IDE of the developer's choice.

\subsection{System Design}

Based on the requirements analysis, a solution comprising a mobile application and a web mapping application was proposed. The design was constrained mainly by the client's requirements for the application to support offline data collection, and for a low-cost solution. The three main deliverables of the proposed solution were a mobile application, a cloud storage solution serving content as a web service, and a web application. The system design is summarized in Figure 3-1. 


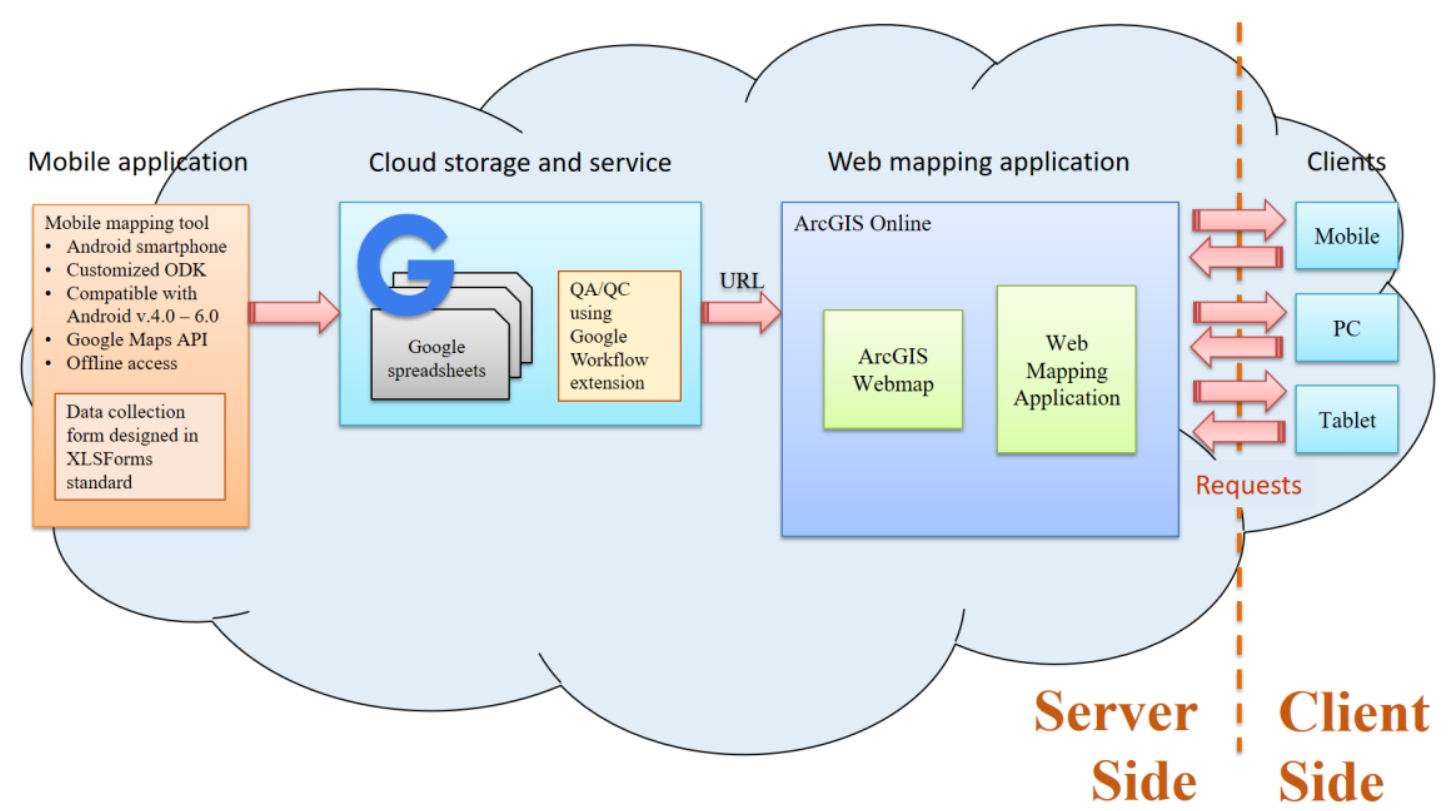

Figure 3-1: System design

\subsection{Project Plan}

The project was planned in three phases over a period of eight months (May to November 2016): system design, application customization, and deployment and testing. Each of the deliverables was subjected to the project management cycle of planning, deploying, and testing. In each phase, the client was consulted and apprised of the development process. Table 3 shows the project tasks for each phase. A more detailed work breakdown schedule is available in Appendix B. 
Table 5. Project tasks by phases.

\begin{tabular}{|c|c|c|c|c|c|c|c|c|c|c|c|}
\hline & \multirow[b]{2}{*}{ Tasks } & \multicolumn{10}{|c|}{ Months* } \\
\hline & & 1 & 2 & 3 & 4 & 5 & 6 & 7 & 8 & 9 & 10 \\
\hline \multirow{4}{*}{ 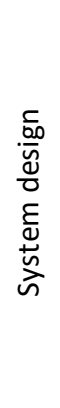 } & Development of system requirements & & & & & & & & & & \\
\hline & $\begin{array}{l}\text { Establishing parameters to be collected by } \\
\text { mobile tool, and workflows to be used (by } \\
\text { client) }\end{array}$ & & & & & & & & & & \\
\hline & $\begin{array}{l}\text { Design of data collection forms based on } \\
\text { workflows provided by the client }\end{array}$ & & & & & & & & & & \\
\hline & $\begin{array}{l}\text { Design and testing of user interface of mobile } \\
\text { mapping tool }\end{array}$ & & & & & & & & & & \\
\hline \multirow{4}{*}{ 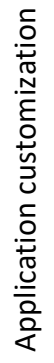 } & $\begin{array}{l}\text { User interface customization using the Android } \\
\text { SDK }\end{array}$ & & & & & & & & & & \\
\hline & $\begin{array}{l}\text { Configuration of database spreadsheet to } \\
\text { make it web-accessible }\end{array}$ & & & & & & & & & & \\
\hline & $\begin{array}{l}\text { Designing of ArcGIS Online webmap of St. } \\
\text { Maarten }\end{array}$ & & & & & & & & & & \\
\hline & Designing of web mapping application & & & & & & & & & & \\
\hline \multirow{3}{*}{ 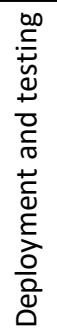 } & $\begin{array}{l}\text { Testing, staging, modification of design based } \\
\text { on client feedback }\end{array}$ & & & & & & & & & & \\
\hline & $\begin{array}{l}\text { Deployment of the tool in St. Maarten (by } \\
\text { client) }\end{array}$ & & & & & & & & & & \\
\hline & $\begin{array}{l}\text { Data collection campaign by the client in St. } \\
\text { Maarten, using stakeholder network (by client) }\end{array}$ & & & & & & & & & & \\
\hline
\end{tabular}

\subsection{Summary}

The requirements analysis process resulted in a system design that met the needs of the client, most importantly a citizen science mobile mapping tool. This chapter reiterated the problem statement. Section 2 went on to discuss the functional and non-functional requirements of both the mobile application and the web mapping application. Section 3 presented the system design that was proposed and agreed upon with the client. Finally, the chapter concludes with the presentation of a project plan in Section 4. This plan consisted of three phases, and several tasks important for the successful implementation of the project. In summary, the chapter provides a very clear understanding of the required functionalities, a system design, and a plan to implement this design. Chapter 4 addresses database development. 


\section{Chapter 4 - Database Design}

This chapter describes the various data models used in the project solution. It begins with Section 4.1 describing the conceptual data model. It was used to abstract the real-world features into entities comprised of various classes and attributes defined in the project. Section 4.2 describes the transformation of the conceptual model into a database design that can be implemented. Section 4.3 describes the various data sources provided by the client, from which the database design was defined. Section 4.4 describes how the data were processed and loaded into the database. Lastly, Section 4.5 summarizes the database design considerations as discussed in the chapter.

\subsection{Conceptual Data Model}

A conceptual data model was developed through consultation with the client, various stakeholders, and coral reef experts. This model was useful in articulating the various entities in coral reef mapping, and how they relate. In this conceptual model, the citizen scientist carries out a survey by reporting on several observations at a specified location. The user may optionally take or upload a photograph, and make additional observation notes. Each survey contains the coral reef species and condition, and the habitat and environmental conditions, as represented in the conceptual model in Figure 4-1.

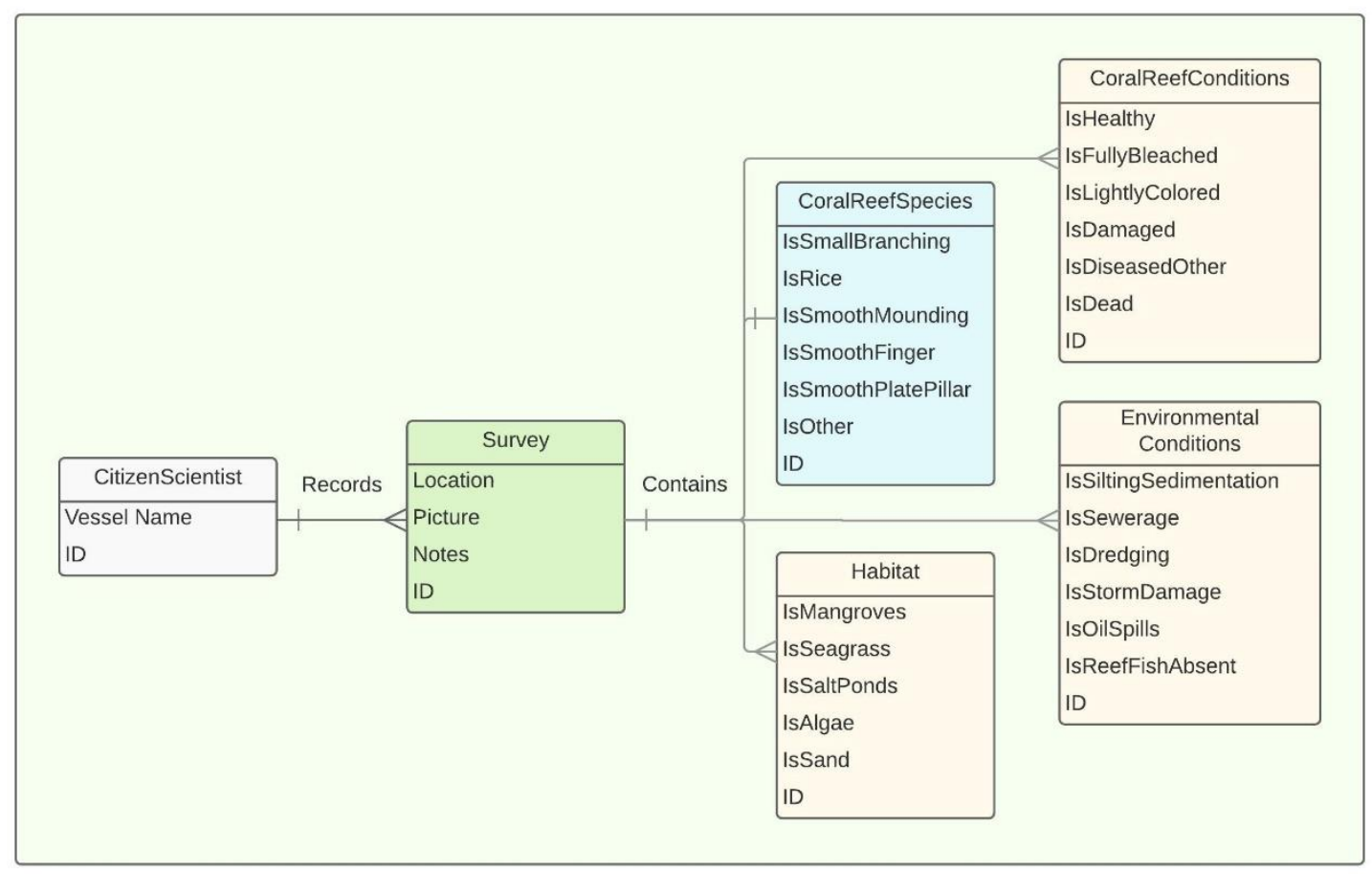

Figure 4-1: Conceptual model of project. 


\subsection{Logical Data Model}

While the conceptual model describes the client's needs abstractly, the logical data model represents the organization of data in the database. The database model chosen was Google Spreadsheets, owing to its cost-effectiveness and flexibility. Google Spreadsheets is hosted for free online on Google Drive, and its CSV data format is supported by most software systems. This makes it easy to move these data across systems. The database comprised two spreadsheets: a coral observations sheet, and an approved coral observations sheet. The following sections discuss the choice of database, the question of database normalization for the spreadsheets, and the schema that was adopted for this database design.

\subsubsection{Choice of Database}

During the design process, there were two options for the database design: a relational database and a flat-file database. The advantages of using a relational database included more robust searching, querying, reporting, and data sharing across networks. These advantages are more significant when working with client/server applications, high volume and high traffic applications, and large datasets.

Flat files on the other hand are simple to implement and parse, are understood by almost all existing applications, and offer faster and more compact manipulation. These advantages influenced the choice of XML (Extended Markup Language) for the project. While this resulted in not being able to take advantage of database normalization, and its accompanying advantages, it allowed for a much smaller learning curve.

\subsubsection{Database Normalization}

Once the flat-file database was adopted in the logical data model design, all the components of the conceptual data model were combined into a single table, i.e. coral reef species and conditions, habitats, and environmental conditions. This violates the database principle of normalization (Codd, 1971). However, the anticipated performance advantages far outweighed the benefit of conforming to this recommended design practice.

\subsubsection{Database Schema}

The two datasets represented coral reef observations before and after quality assurance. These spreadsheets contained location data as longitude and latitude fields, and the various coral reef observations, including information such as type of coral, condition of coral, environmental concerns, and habitats. Some of the data were designed to be collected internally by the device, while others required user input. Table 6 shows a section of the schema for the coral reef observations dataset. 
Table 6. Schema for observations dataset.

\begin{tabular}{|c|c|c|}
\hline Field & Data Type & Description \\
\hline locationLatitude & Float & Internal data \\
\hline locationLongitude & Float & Internal data \\
\hline locationAccuracy & Float & Internal data \\
\hline observationDate & Date & Internal data \\
\hline instancelD & text & Internal data \\
\hline Observations & Text & $\begin{array}{l}\text { Coded Domain: } \\
\text { "Coral Condition" : "coral_condition" } \\
\text { "Environmental Condition" : "environmental_condition" }\end{array}$ \\
\hline Coral_Type & Text & $\begin{array}{l}\text { Coded Domain: } \\
\text { "Small branching" : "Branching" } \\
\text { "Rice" : "Rice" } \\
\text { "Smooth mounding" : "Mounding" } \\
\text { "Smooth finger" : "Finger" } \\
\text { "Smooth plate and pillar" : "Plate" } \\
\text { "Other / Don't know" : "other" }\end{array}$ \\
\hline Coral_Condition & Text & $\begin{array}{l}\text { Coded domain: } \\
\text { "Healthy" : "healthy" } \\
\text { "Diseased / slightly bleached" : "diseased" } \\
\text { "Damaged/broken" : "damaged_broken" } \\
\text { "Dead / fully bleached" : "fully_bleached" } \\
\text { "Other / don't know" : "dead" }\end{array}$ \\
\hline Environmental_Concerns & Text & $\begin{array}{l}\text { Coded domain: } \\
\text { "Silting/Sedimentation" : "silting" } \\
\text { "Sewerage" : "sewerage" } \\
\text { "Dredging" : "dredging" } \\
\text { "Storm damage" : "storm" } \\
\text { "Oil/Chemical spill" : "oil_spill" } \\
\text { "Reef fish absent" : "no_fish" } \\
\text { "Other pollution" : "pollution" }\end{array}$ \\
\hline Habitats & Text & $\begin{array}{l}\text { Coded domain: } \\
\text { "Mangroves" : "mangroves" } \\
\text { "Seagrass" : "seagrass" } \\
\text { "Salt ponds" : "salt_ponds" } \\
\text { "Algae" : "algae" } \\
\text { "Sand" : "sand" } \\
\end{array}$ \\
\hline Notes & Text & Observation notes (user input) \\
\hline Approved & Binary & $\begin{array}{l}\text { "Yes" : "1" } \\
\text { "No" : "0" }\end{array}$ \\
\hline
\end{tabular}

\subsection{Data Sources}

As demonstrated above, data played a significant role in the successful implementation of the coral reef mapping tool. Data relating to coral reefs in St. Maarten was not readily 
available at a national scale, hence the need for the tool. Additional data were collected to support the display, visualization, and analysis of the St. Maarten coral reef data, in the web mapping application. These ancillary datasets were identified as including both basemaps and operational layers.

\subsubsection{Basemaps}

Several ArcGIS Online basemaps were reviewed and those with the highest resolution of data for St. Maarten were the OpenStreetMap (OSM) basemap, and the World Imagery basemap. Both were already published to the ArcGIS Online imagery gallery by Esri and came with a detailed metadata. More detailed metadata for the OSM basemap was derived from OSM (OpenStreetMap, 2016). The imagery layer covered St. Maarten at a scale ranging from 1:288,000 to 1:72,000 based on SPOT 2.5m imagery. Esri's World Ocean basemap was also included despite its poor display resolution at the desired scale of 1:100,000, due to its detailed ocean feature descriptions.

\subsubsection{Operational Layers}

The operational layers are dynamic and focused layers in a web mapping application. They are responsive, draw quickly, and report details on a mouse click. The operational layers for this project were provided by the client in Shapefile format, along with their metadata, and covered St. Maarten. The following five operational layers were used:

- St. Maarten Coral Reef Observations - point features showing the locations of coral reefs in St. Maarten as collected using the coral reef mapping tool.

- Global Coral Reefs - point features showing locations of coral reefs around the world with the following attributes: reef system, reef type, reef name, water depth, country name, island name, and whether reef is protected or not.

- Dive Sites - point feature class representing popular diving locations in St. Maarten with the sole attribute of name.

- Marine Protected Areas (MPAs) - polygon feature class with the following attributes: MPA boundaries, MPA zones (traffic, industrial, conservation, and anchorage), inland water, and mainland.

- Points of Interest (POIs) - this point feature class represents POIs in St. Maarten, with a POI name and type attribute (view point, airport, dive site, and so on).

Table 7 summarizes the data that were used in the web mapping application, and where they came from. 
Table 7. Data sources.

\begin{tabular}{|l|l|l|}
\hline \multicolumn{1}{|c|}{ Data } & \multicolumn{1}{c|}{ Source } & \multicolumn{1}{c|}{ Format } \\
\hline St. Maarten coral reefs & N/A - data obtained from tool & Shapefile \\
\hline Global coral reefs & Reef Base & Shapefile \\
\hline Dive sites & Nature Foundation of St. Maarten & Shapefile \\
\hline $\begin{array}{l}\text { Marine Protected Areas } \\
\text { (MPAs) }\end{array}$ & Nature Foundation of St. Maarten & Shapefile \\
\hline Points of Interest (POIs) & Nature Foundation of St. Maarten & Shapefile \\
\hline
\end{tabular}

\subsection{Data Scrubbing and Loading}

All the data received were in Shapefile format and had geographic coordinate systems in World Geodetic System Datum 1984 (WGS84). The data were imported into a File Geodatabase and re-projected into the Web Mercator (Auxiliary Sphere) projection, upon which ArcGIS webmaps are based. Figure 4-2 illustrates the data loading workflow.

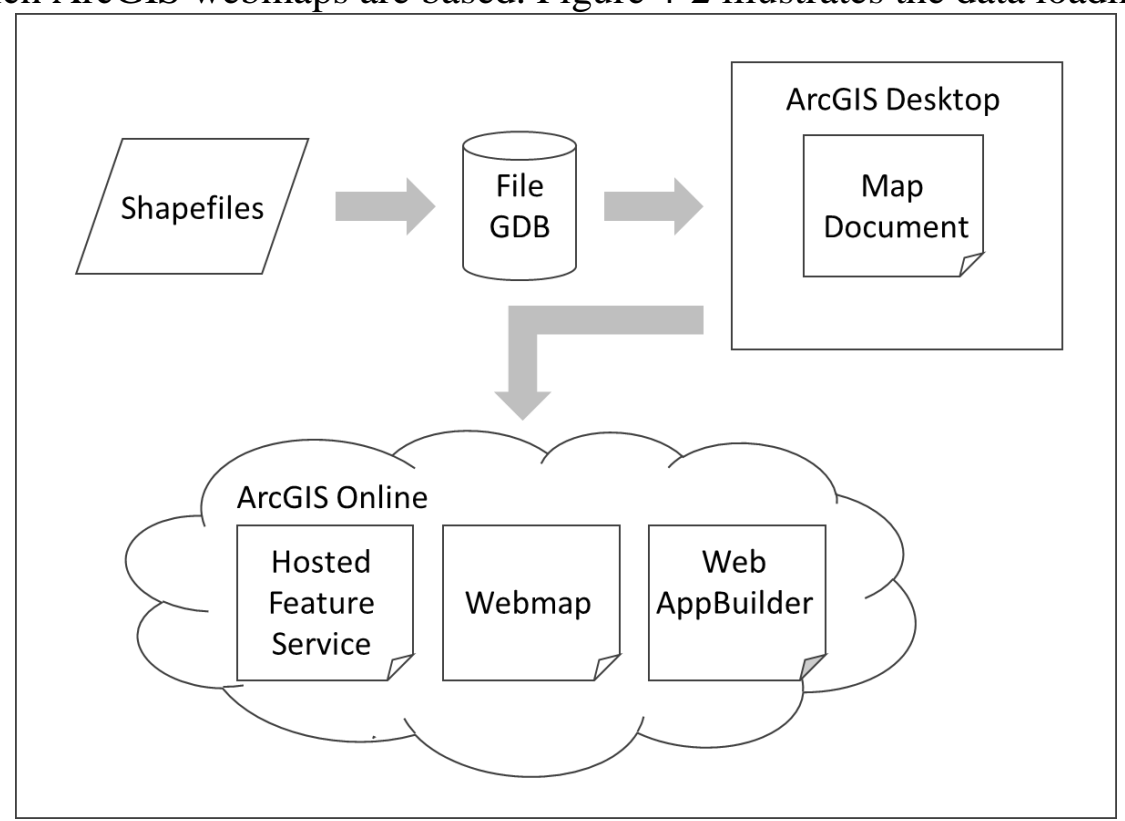

Figure 4-2: Data loading into ArcGIS Online.

\subsection{Summary}

This chapter reviewed the conceptual data model for the client's problem and how coral reef observation data and results were organized. Specifically, Section 4.2 discussed the design and database choices supporting the logical data model, and why a flat non-2NF (second order normal form) database was preferred over a relational database. Section 4.3 discussed the various data sources of data used in the web mapping application, while Section 4.4 discussed how these data were loaded into ArcGIS Online. 



\section{Chapter 5 - Implementation}

Two applications were developed to meet the client's requirements: a mobile application, and a web application. The mobile application was designed to enable citizen scientists and recreational divers to record their coral reef observations, either on board a boat after a series of dives, or much later. The web application was designed for users interested in viewing coral reef information of St. Maarten, and showed the observations collected with the mobile application, along with other relevant data.

This chapter describes the implementation of both the mobile and the web application. Section 5.1 discusses the mobile application user interface. Section 5.2 discusses the design and development of the data collection application, including user interface design in XForms and customization of the mobile application. Section 5.3 discusses the configuration of the cloud storage environment. Section 5.4 discusses the design and configuration of the web application. Section 5.5 summarizes the implementation procedures for the project.

\subsection{Mobile Application User Interface}

The development of the mobile application began with converting the client's needs into functional and non-functional requirements, in accordance with the chosen implementation strategy. This was supported by developing user stories and workflows.

\subsubsection{User Stories and Workflows}

User stories are short, simple descriptions of processes for users, as told from their perspective. For instance, "As a user, I would like to take a photograph of the observed coral, and add it to my report." Through discussions with the client and coral reef experts, such user stories were captured and developed into a workflow that the citizen scientist could follow when using the coral reef mapping tool. The workflow is shown in Figure $5-1$. 


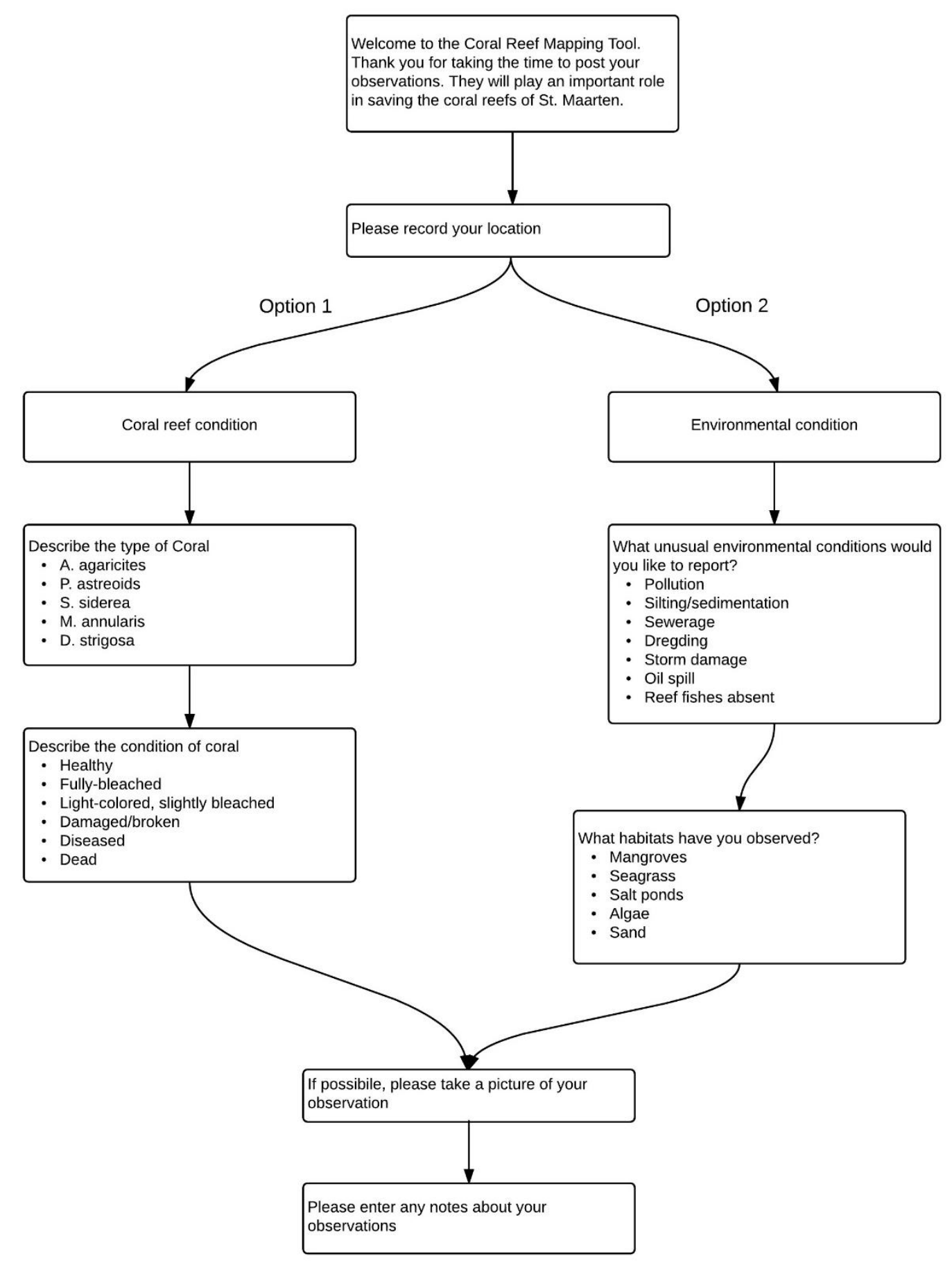

Figure 5-1: Coral reef mapping tool user workflows.

\subsubsection{User Interface Design}

Before the actual development of the tool began, a user interface was designed using wireframes. Wireframes are simple outlines or skeletons of the various pages of the application. They help visualize what the finished application might look like, focusing on the layout, content placement, and navigation of pages. They are easy to adjust, 
therefore saving the developer time that would have been spent editing layouts that might have taken long to develop.

NinjaMock (2016), a free online tool, was used for this. Figure 5-2 shows two examples of views created through this process (see Appendix A for all the views). These views were discussed and agreed upon with the client.
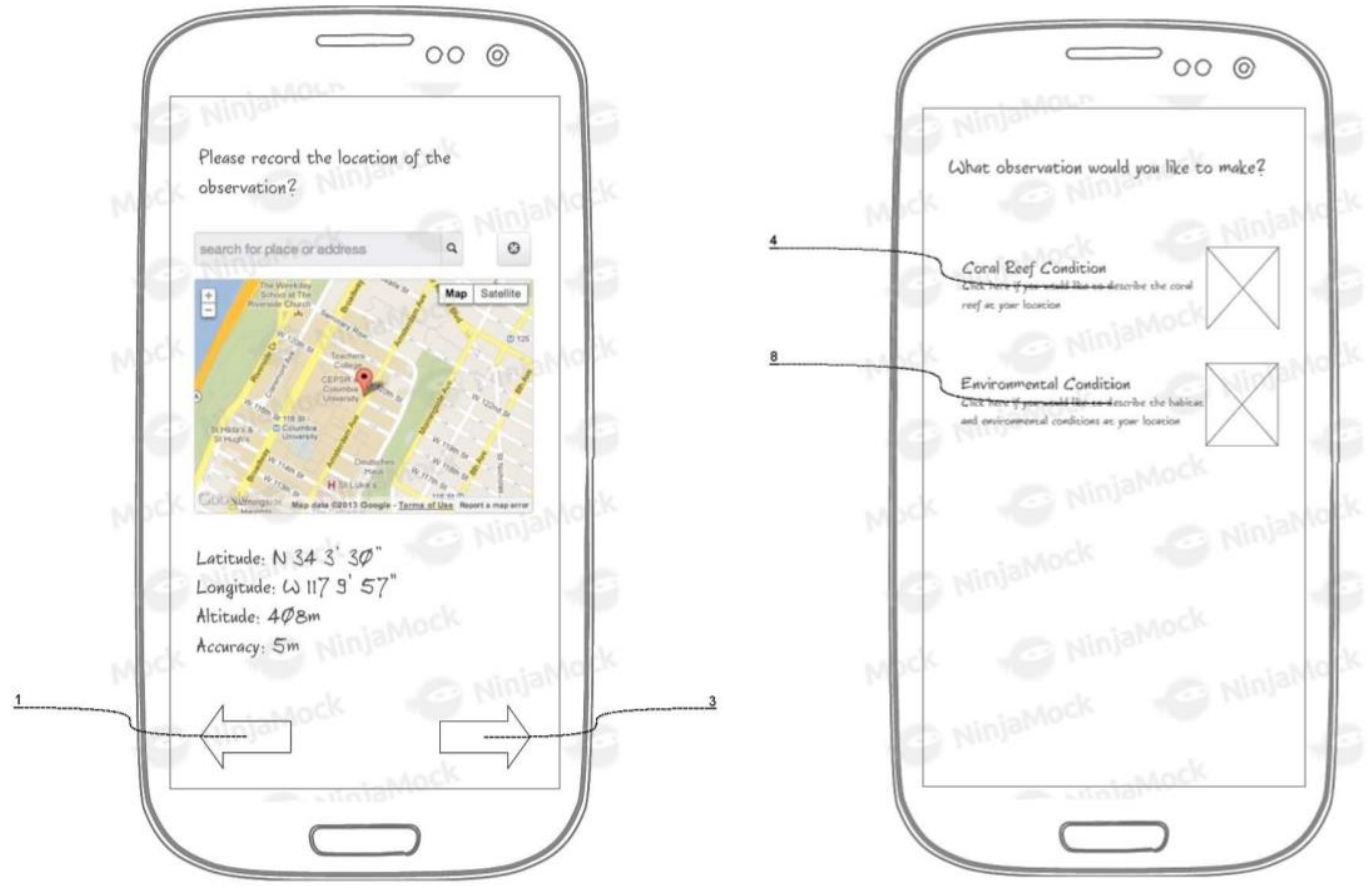

Figure 5-2: Examples of the mobile application wireframes.

\subsection{Data Collection Application Development}

The main supporting technology used in the development of the data collection application was Open Data Kit (ODK) (Hartung et al., 2010). ODK is a set of free and open source tools developed by the University of Washington's Department of Computer Science and Engineering under an Apache 2.0 (2004) license. These tools can be used to create a mobile data collection solution for Android, with support for data submission to an online server.

Out of the box, ODK consists of three modules: build, aggregate, and collect. Using these tools a user can build a form, setup a server, and publish mobile data to that server respectively. The user can design a simple form in a web-based drag-and-drop application with the build module. The user can fill in a data form and upload it to the data server using the collect module. The aggregate module is a web application that supports hosting of the survey data. It can be deployed to a local computer, an organizational server, or a cloud environment such as the Google App Engine.

To meet the requirements of this project, the aggregate module was deployed as an out-of-the-box solution using the Google App Engine storage environment. This circumvented the challenges of setting up and managing a scalable database and web services. The collect module was customized to meet the specific requirements of the 
client. Lastly, instead of using the build tool, the XForm was configured directly in XML using an XML editor.

\subsubsection{Setup of the Development Environment}

Google's Android Studio (2016) version 2.2.2 was chosen as the Integrated Development Environment (IDE) (see Figure 5-3). There are three major components to building an Android application, regardless of the choice of IDE, with the trend being to separate the programming code from the user interface design:

- User interface: This usually consists of a set of XML files, describing the interface in terms of screen layouts and navigation, and the associations between them. This project used XForms to describe the navigation logic: the contents of each page view, the relative order of the views, and how users navigate to each view based on the choices they made. Android Studio's AndroidManifest. xml file was key in managing how the various activities were associated.

- Resources: This includes various graphics, language translations, animations, and other non-code assets that are dynamically loaded at runtime. This project used the Android Studio's default "res" directory.

- Code: This component consists of a collection of classes and interfaces containing sources code to load the layouts and menus, and to respond to various events from the interface. This project used Java code, contained in a "java" directory.

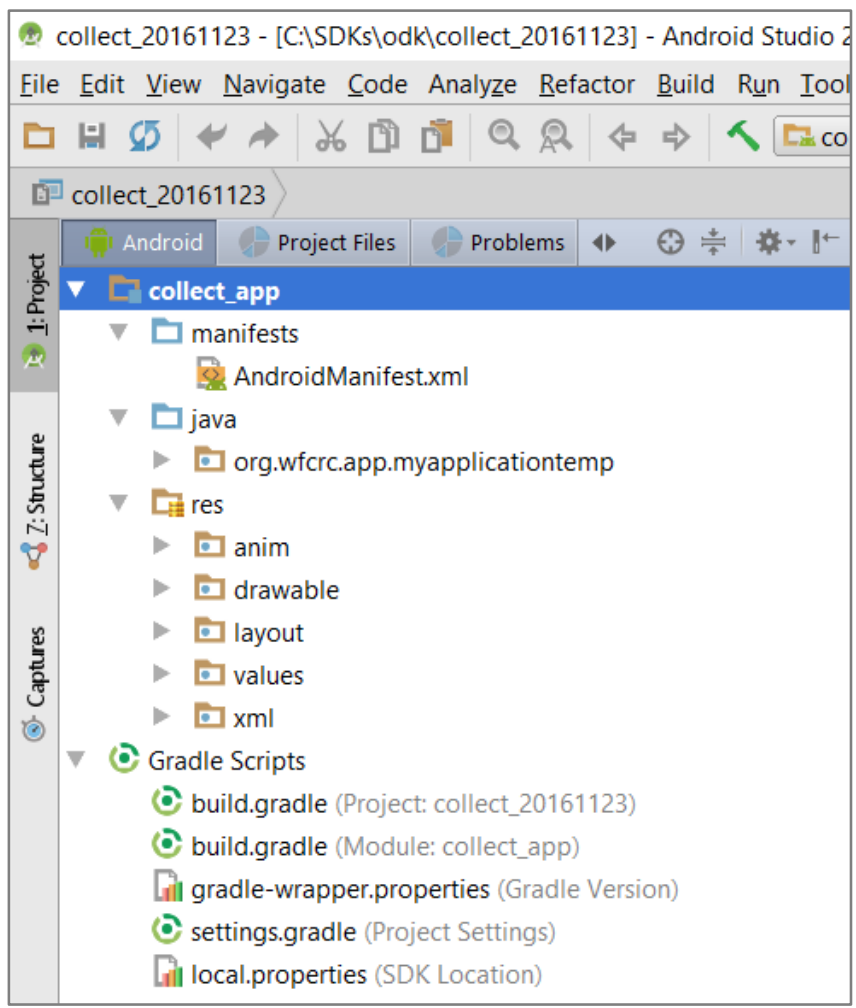

Figure 5-3: Android Studio IDE. 
The application was deployed with a target SDK version of 24, and a minimum SDK version of 15, representing Android versions 7.0 and 4.0 respectively. This means that the application could run on any android version between 4.0 and 7.0. Testing was done on a Sony Xperia Z3 running Android version 6.0.1. The phone has a 5.2-inch display of resolution 1080 x 1920 pixels.

\subsubsection{User Interface Design from XML}

The XForms specification was used to design the data entry forms (Boyer, 2009). XForms is an increasingly popular XML-based form description standard designed by W3C for the next generation of web-based forms. Being XML-based, it can easily be used in mobile development to design mobile interfaces. It simplifies designing of mobile data collection forms, enabling users to design complex forms with many capabilities for use in different systems and environments. An XForm contains two main sections, represented as multiple XML tags:

1. A $<$ model $>$ section describes the database model. It contains an $<$ instance $>$ tag that defines the database name, where the form will be stored as a set of tables, and $\langle\mathrm{b}$ ind $>$ tags that describe how the data variables will be stored; their data types, constraints, and any conditions that they must meet. Each variable that is added to the instance section represents a user prompt in the application. As soon as the XForm is published to the cloud storage environment (Google App Engine), the database and the relevant database tables are created based on the information from this section.

2. A $\langle\mathrm{body}>$ section determines how the various screen prompts are rendered to the user. In the tag's attributes, appearance defines the type of widget or prompt that the user will encounter, while ref informs the system where the data will be stored. The relevant attribute sets conditionality, causing the view to only appear when a condition is met. The $<l$ abel $>$ tag defines what will appear in the header of the prompt, while the optional $<$ hint $>$ tag defines additional text that will be displayed in the view.

This project's XForm was developed as shown in the excerpt in Figure 5-4. Notepad++, a free text editor, was used to create this form in XML. Guidelines from the ODK website (2016, November 11) were followed .

The database instance was specified as coral_observations_v0. Nine prompts were specified: location, observations, coral_type, condition, picture, environmental_concerns, habitats, notes, and observation_date. Several datatypes were specified as geopoint, select1, binary, select, and string. Select1 refers to a single selection option, while select refers to a multiple selection, based on the XForms specification. The attribute appearance="quick" was interpreted by the system as a direction to auto-navigate to the next view as soon as the user selected an option. The full XForm can be found in Appendix B. 


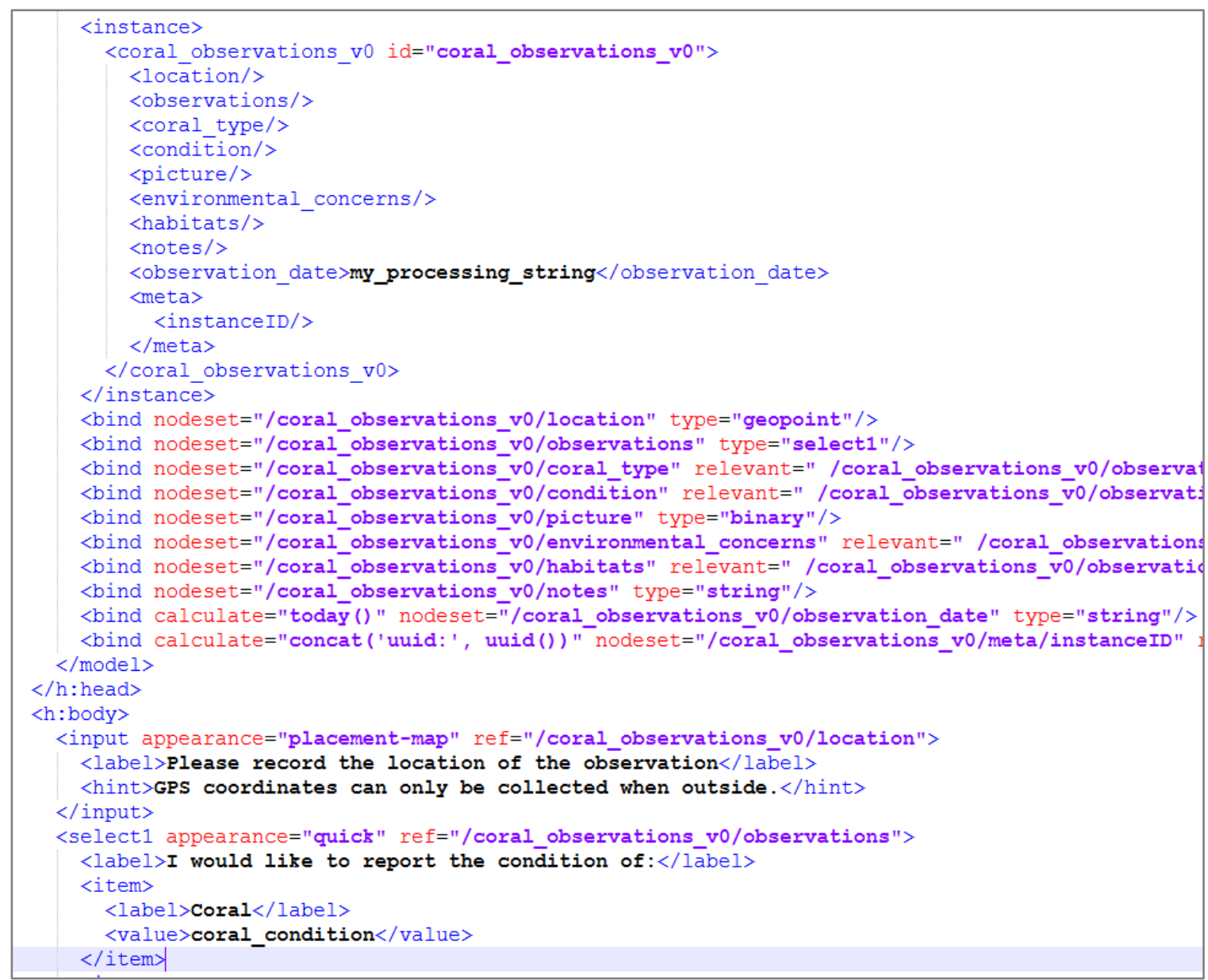

Figure 5-4: Excerpt from XForm.

The XForm was tested on an emulator to ensure that everything was read correctly, contained the required hints and prompts, and generally functioned as expected. The Formhub website (2016, November 11) was used for this. Some functionalities relating to mobile auxiliary devices could not be tested due to a limitation in the emulator.

\subsubsection{Mobile Application Customization}

Customization of the mobile application occurred in the Android Studio environment that was described in the preceding section. These customizations involved changing the look and feel of the application to give it the client's branding. Other changes were done to move some objects around and remove others, to make the application easier to understand and use by a novice user.

By default, the mobile application came with a geopoint location view that simply obtained the location of the user using either the device's GPS, mobile network, or Wi-Fi; it did not display this location on a map. To improve on this, mapping capabilities from Jon Nordling's GeoODK (2015) Open Source tool, distributed under the Apache 2.0 license (2004, November 30), were used. The process involved integrating the GeopointMapActivity - java class from Nordling's source code, and the 
accompanying geopoint_layout.xml, and updating the AndroidManifest. xml file accordingly.

A welcome screen was inserted and assigned the appropriate text by editing the form_entry_start.xml and strings.xml files. A Saved Layers button was removed from the map view, as it was not required. The user workflow discussed in Section 5.1 did not require the user to save any maps. This involved making some modifications to the GeoPointMapActivity.java and the geopoint_layout.xml files respectively.

The order of the buttons in the image capture widget was reversed. This was to ensure that the option to select an image appeared above the option to take a picture on the screen. In the envisioned workflow, most users would upload an already saved image, rather than taking a picture.

The data submission page was cleaned up and unnecessary content removed. The default option gave the user several options that were not useful for a novice user. Rather than completely removing these options, they were taken out of sight, so that the processes still occurred in the background, but the user was not aware of this (Figure 5$5)$.
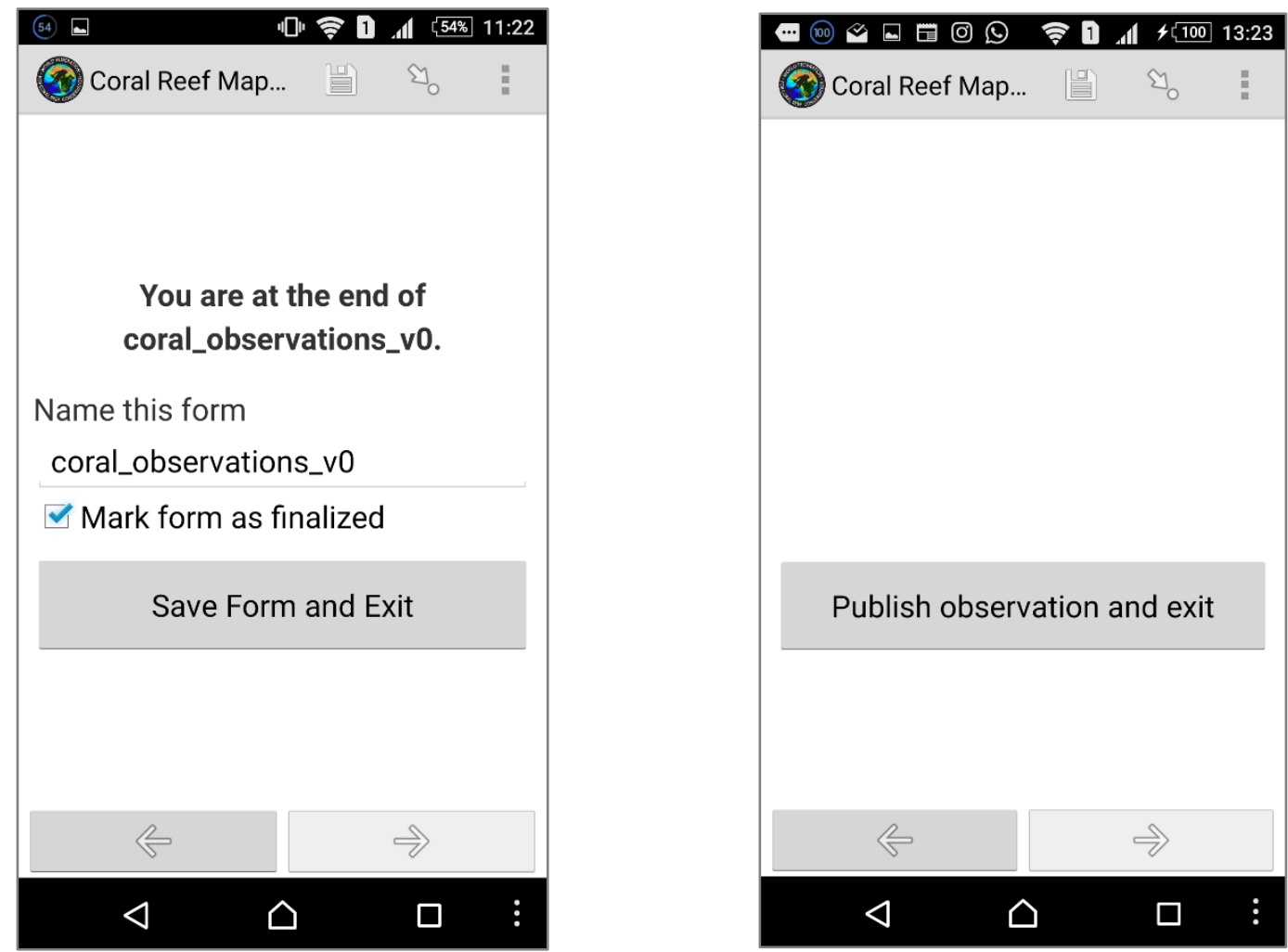

\section{Figure 5-5: Clean-up of data submission page (before and after views).}

The subsequent edit involved removing the "Zoom to saved feature" button from the map view pop-up that appears shortly after the map view is launched. Since the user is not saving any features to the map, this button was not required and was removed. The resulting pop-up only showed the "Zoom to current location" option, as shown in Figure 5-6. 


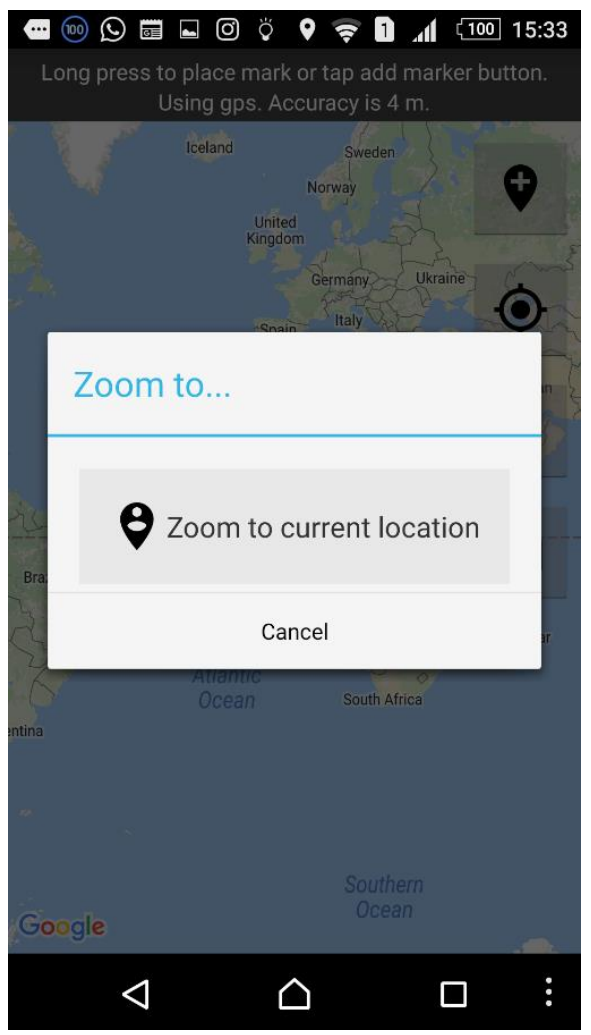

Figure 5-6: Map view pop-up. files:

This change was accomplished by editing several code segments in the following

- GeopointOsmMapActivity.java

- GeopointMapActivity.java

- GeoshapeGoogleMapActivity.java

- Geopoint_zoom_dialog.xml

Once the application had been installed on the device, a shortcut was created. This was a direct link to the data collection form on the homepage of the device and in the list of applications. It was created by long-pressing on the home screen. Upon releasing it, a menu appeared. Under Settings, the Create shortcut option was chosen, and Coral Observations Form selected from the displayed list (see Figure 5-7). This streamlined the coral reef observations workflow, saving the user from the trouble of going through the Main Menu for every observation; instead the user launched straight into the data collection process. 


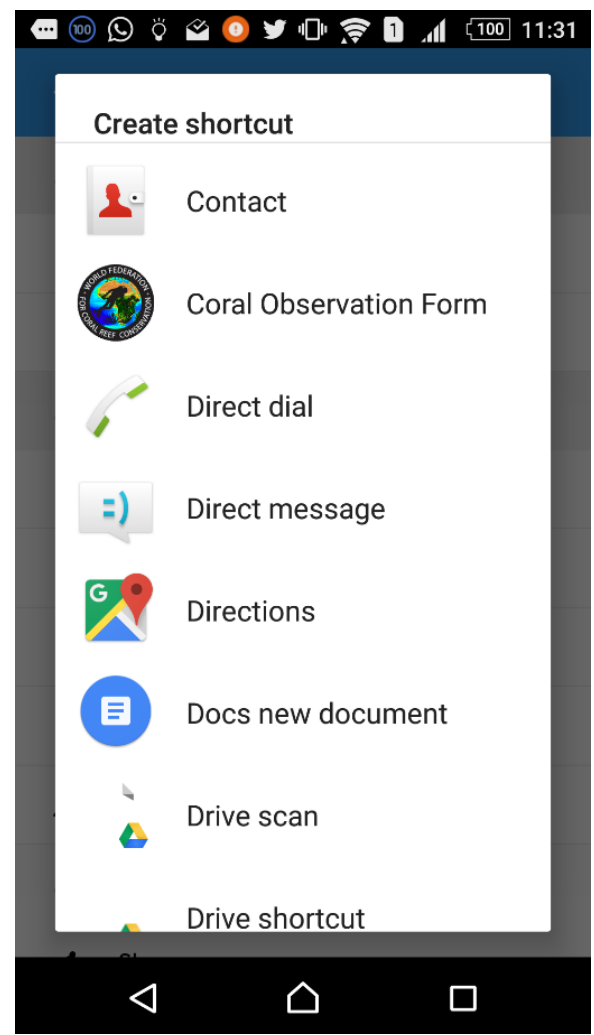

Figure 5-7: Dialog for creating a shortcut for the application.

\subsection{Configuration of a Cloud Storage Environment}

As mentioned in the preceding section, ODK Aggregate was used as an out-of-the-box solution for a server and data repository. This was deployed on Google App Engine, a Platform-as-a-Service (PaaS) solution for developing and hosting web applications on Google Cloud Platform. Google App Engine is free up to a certain quota for each of the resources that it provides, making it suitable for scalable applications (Table 8).

Table 8. Google App Engine free quota limits.

\begin{tabular}{|l|c|}
\hline \multicolumn{1}{|c|}{ Resource } & Quota limit \\
\hline Apps per developer & 10 \\
\hline Time per request & 30 seconds \\
\hline Files per all & 3,000 \\
\hline HTTP response size & $10 \mathrm{MB}$ \\
\hline Datastore item size & $1 \mathrm{MB}$ \\
\hline Application code size & $150 \mathrm{MB}$ \\
\hline $\begin{array}{l}\text { Blob store storage size } \\
\text { limit }\end{array}$ & $50 \mathrm{MB}$ \\
\hline
\end{tabular}




\subsubsection{Web Application Datastore}

The web application used Datastore, a database based on Google BigTable, the default Google App Engine database. This is a NoSQL distributed data store that has no schema, and has a high replication of data. It therefore does not support data abstraction, and has limited queries, but provides an API that supports the automatic scaling of applications. It supported the storage of XForms with little restriction on content and size. Each XForm was maintained in its own independent set of tables. Each image was stored in a separate table-set as a binary attachment.

\subsubsection{Web Application Deployment and Configuration}

Deploying the web application involved creating a new Google App Engine project, referenced by the URL: https://coral-observations.appspot.com. Within the API Manager, the following three application APIs were enabled: Google Maps JavaScript API, Drive API, and Fusion Tables API. These supported publishing from Google App Engine to Google Sheets and Fusion Tables, and viewing content in Google Maps, if needed. A Google Maps API key was created, and inserted into the mobile application's AndroidManifest. xml to enable the map to display in the map view. Once this environment had been set up, the aggregate module was uploaded.

The web application supported publishing data to several platforms, including Google Spreadsheets, Google Fusion Tables, and Z-ALPHA JSON. Google Spreadsheet was the preferred format, based on its support for data quality control using Google Drive tools. The option selected was to upload existing content and stream new submissions as they become available, as shown in Figure 5-8.

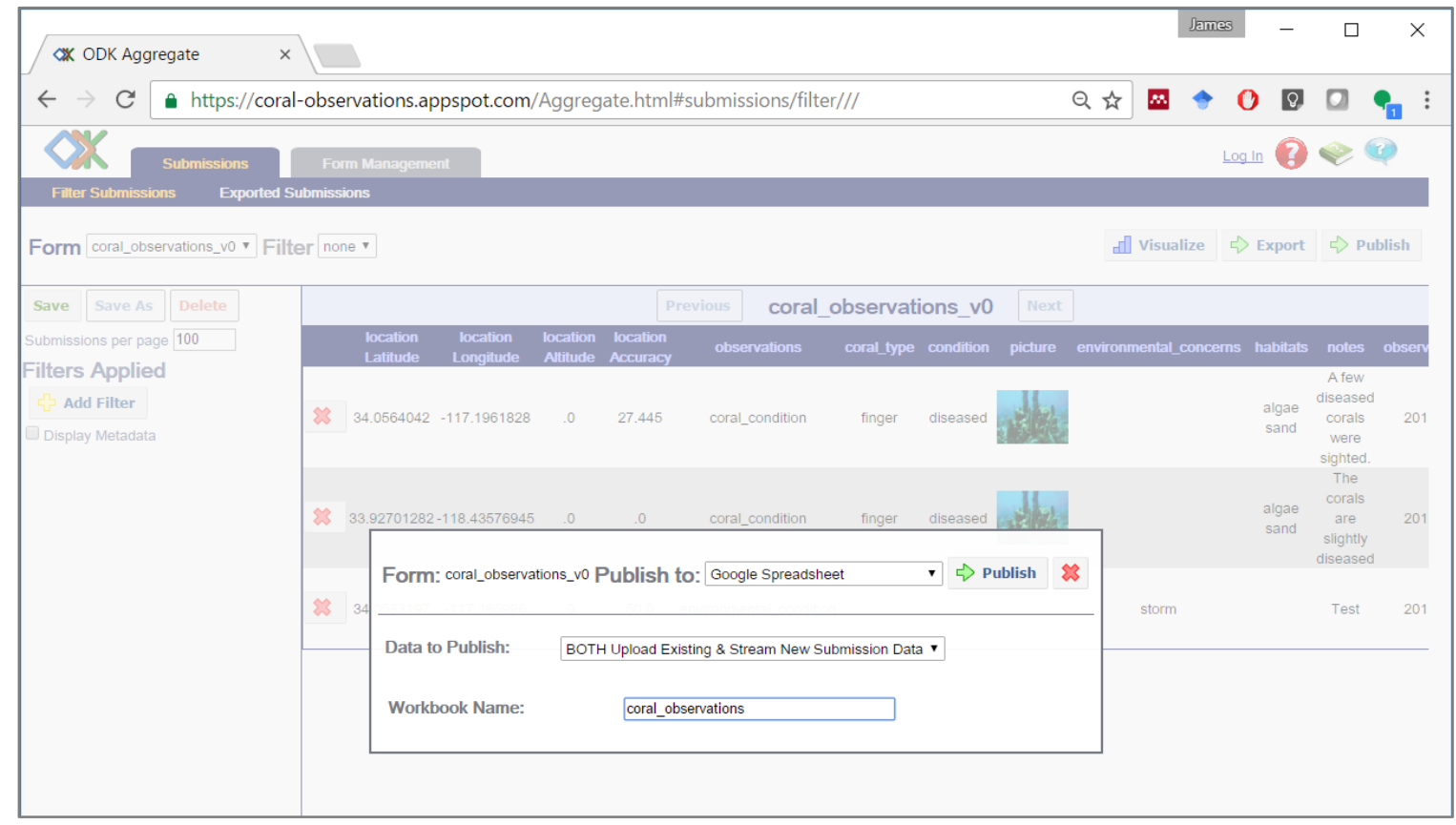

Figure 5-8: Publishing to Google Spreadsheets 


\subsubsection{Web Application Data Quality Control}

Data quality control was done in Google Drive using several tools. This involved performing checks on the published coral reef observations to ensure that they met the required quality standards. The following workflow was designed: the system sends the data administrator a notification email as soon as a new observation is published from the mobile application. The administrator then reviews the publication. Once approved, this record is then published to a new Google Spreadsheet that is publicly available.

Several Google Drive tools and operations supported the quality control workflow. The IMPORTRANGE() function was used to publish the data into a new spreadsheet, based on schema that matched a Google Form that was to be used. The Google Form was used to provide a user-friendly interface for the data administrator to approve the data. Google Drive's formMule and CopyDown add-ons were used to send email notifications to the data administrator, based on an update trigger. Figure 5-9 shows the configuration interface of formMule.

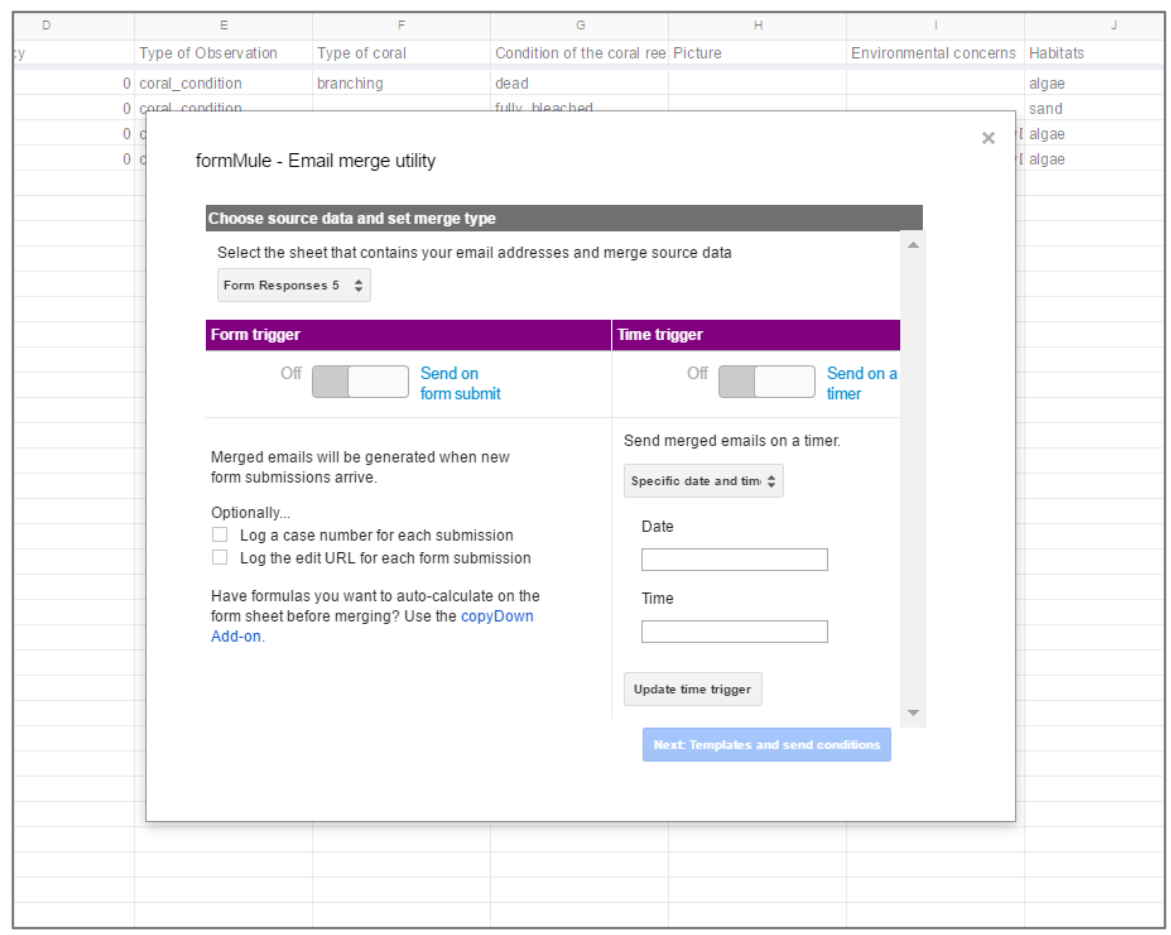

Figure 5-9: Google formMule configuration.

A template was created to email the new observation as a Google Form to the data administrator. The content of the email template was a pre-filled URL containing the duly-filled Google Form. Figure 5-10 shows the interface for configuring the email template from fields in the table. 


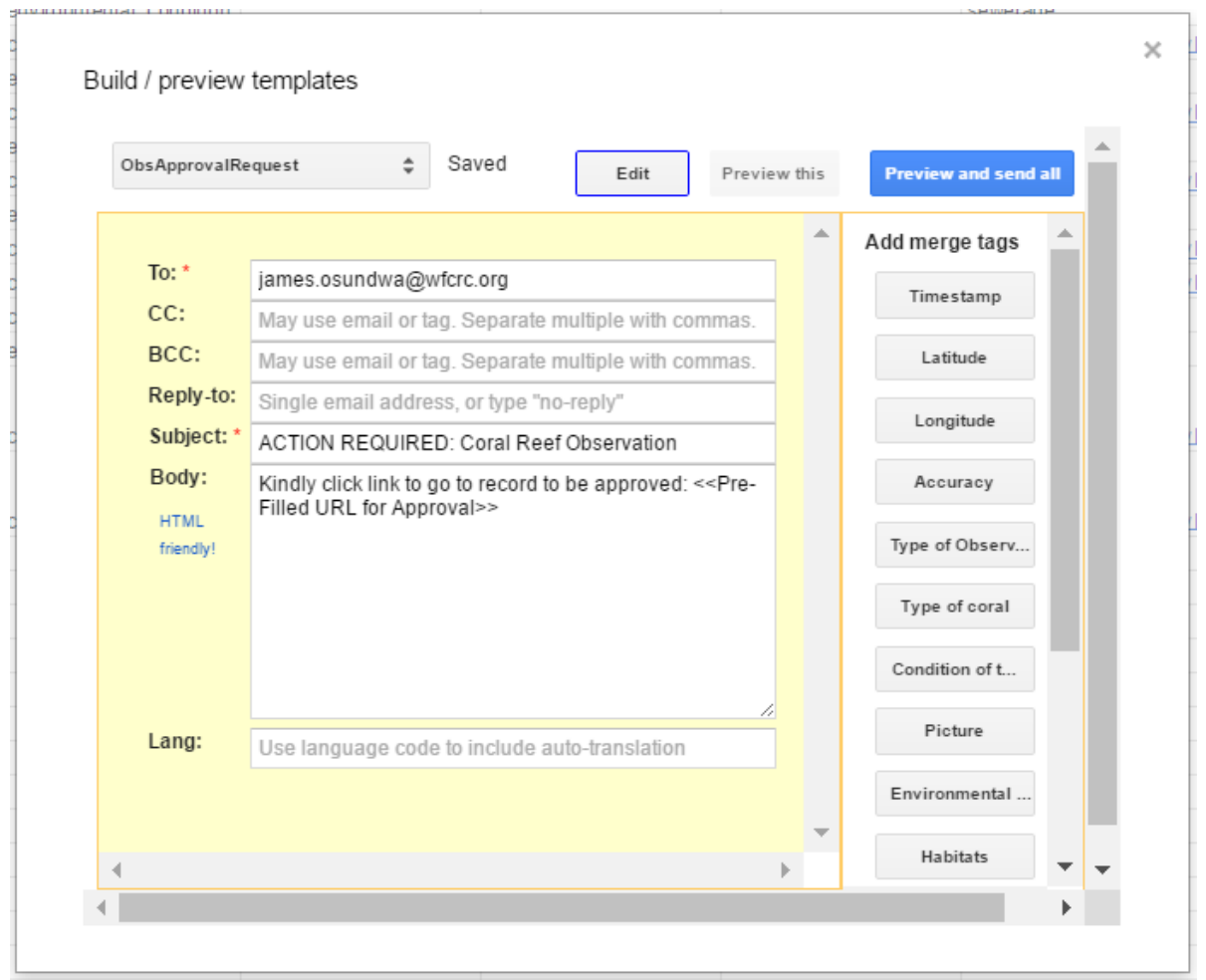

Figure 5-10: FormMule email template configuration.

The complete quality control workflow is shown in Figure 5-11. The process was dynamic with each of the datasets updating automatically with every update. The resulting output was a clean CSV web service that could be consumed by ArcGIS Online, containing only the required data fields. 


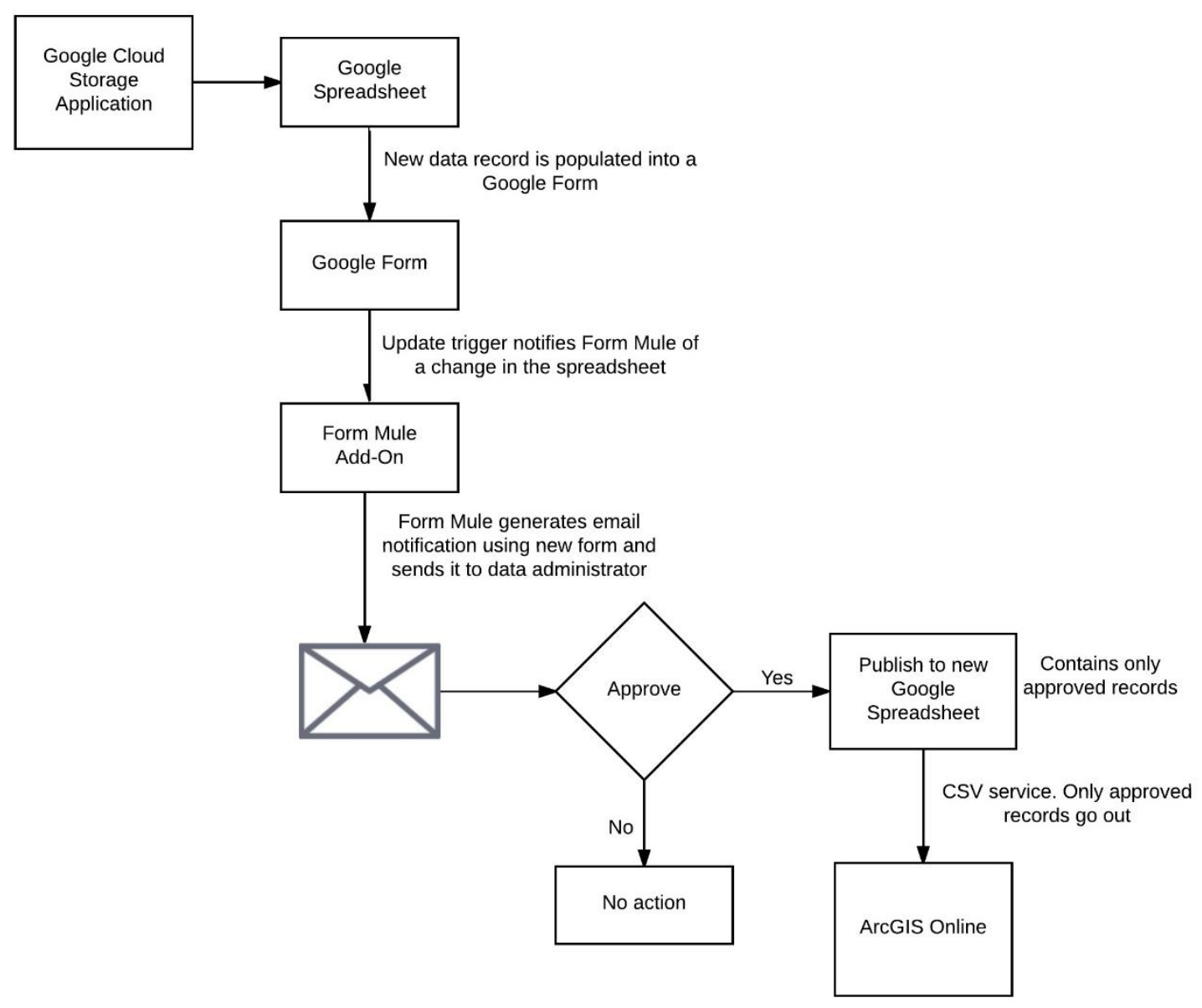

Figure 5-11: Data quality control workflow in Google Drive.

\subsection{Web Mapping Application Development}

The main technology used in the development of the web mapping application was ArcGIS Online. Pinde Fu (2015) describes ArcGIS Online as a "collaborative, cloudbased platform for creating, managing, sharing, and accessing maps, applications, and data." It provides cloud storage, where data can be uploaded and served as web services, an online platform with templates supporting web GIS application development, and a wealth of user-generated basemaps, thematic maps, and analytical services. This combination of capabilities informed the choice of ArcGIS Online, over Google and other possible web mapping environments.

An ArcGIS Online for Organizations account with a publisher role was required to publish hosted web services and applications to ArcGIS Online. A provisional account was used for this purpose, with plans to migrate to the client's ArcGIS Online for Organizations account when it becomes available.

Web AppBuilder, a configurable ArcGIS Online template, was used to build the web mapping application. Web AppBuilder enables users to build web applications without programming. It is based on JavaScript and builds responsive web applications that are cross-platform. Web AppBuilder comes with over a dozen widgets and tools that enable 
various capabilities such as map navigation, attribute table display, search, query, and charting.

The requirements for the web mapping application were that it should display an OpenStreetMap basemap of St. Maarten, POI locations, and coral reef observations from the mobile application, along with their descriptions. Further, it was to be simple to use, and work on desktop, tablet, and smartphone. Based on these requirements, a simple viewer with only the most basic functionalities was used; none of the available widgets was customized.

Based on the existing configuration, the coral observations were set to refresh once every minute. New observations, once approved by the data administrator in the Google cloud, were set to therefore almost instantaneously appear in the web mapping application.

\subsection{Summary}

This chapter addressed the actual implementation of the project, providing a detailed guide as to how the project was implemented. Section 5.1 discussed the mobile user interface, and how this was designed through user stories and interface design. Section 5.2 looked at setting up the development environment, user interface development in XML, and customization of the mobile application. Section 5-3 discussed the cloud storage environment configuration, and the data quality control process. Lastly, Section 5-4 discussed the design and configuration of the web mapping application. 


\section{Chapter 6 - Use Cases}

A use case is a list of steps that a user employs to interact with a system to achieve a goal. This chapter discusses three use cases representing: how the mobile application is used to collect data, how the data administrator manages the quality control in the cloud storage, and how the novice end user works with the web application.

\subsection{Use Case 1: Mobile Application}

This use case looks at how a user can use the mobile application, based on the data collection workflow that was developed in Chapter 5. When the user launches the application, it opens with an introductory splash screen, explaining the importance of the contribution they are about to make. Navigating to the next step brings the user to a view where they can record the location of the observation as shown in Figure 6-1.
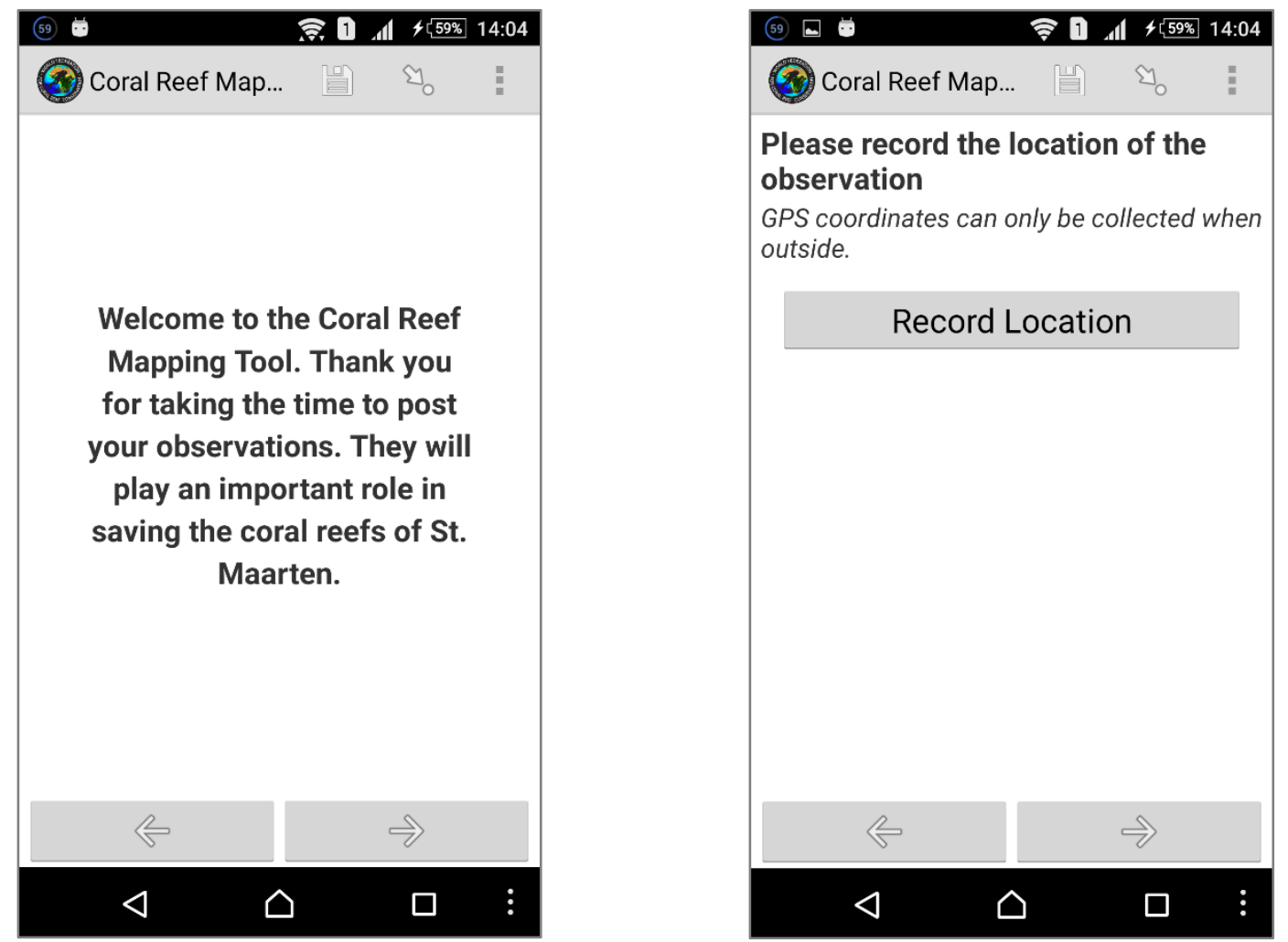

Figure 6-1: Splash screen and record location.

Clicking the Record Location button launches the map view, and then a pop-up with an option to zoom to the current location. The map has options to set location, zoom to GPS location, delete location, and save location as illustrated in Figure 6-2. 

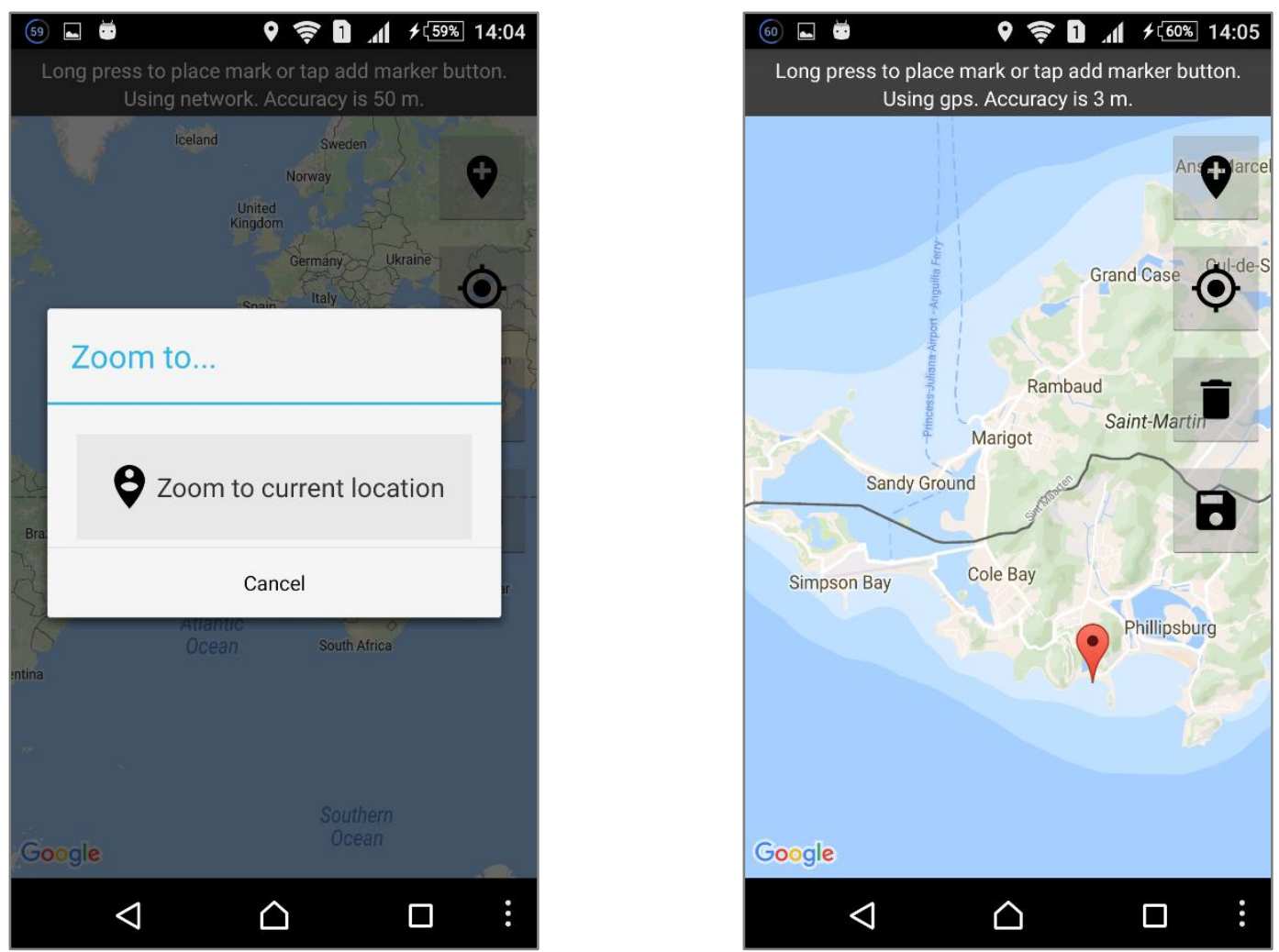

Figure 6-2: Record location map.

Navigating to the next view, the user is presented with a choice between making an observation of coral condition or environmental condition. Choosing to report on coral takes the user through describing the type of coral observed, and its condition. Choosing to report on environmental condition takes the user to a view where they report on what environmental condition they observed that is causing them concern. These two views and their respective options are shown in Figure 6-3. 

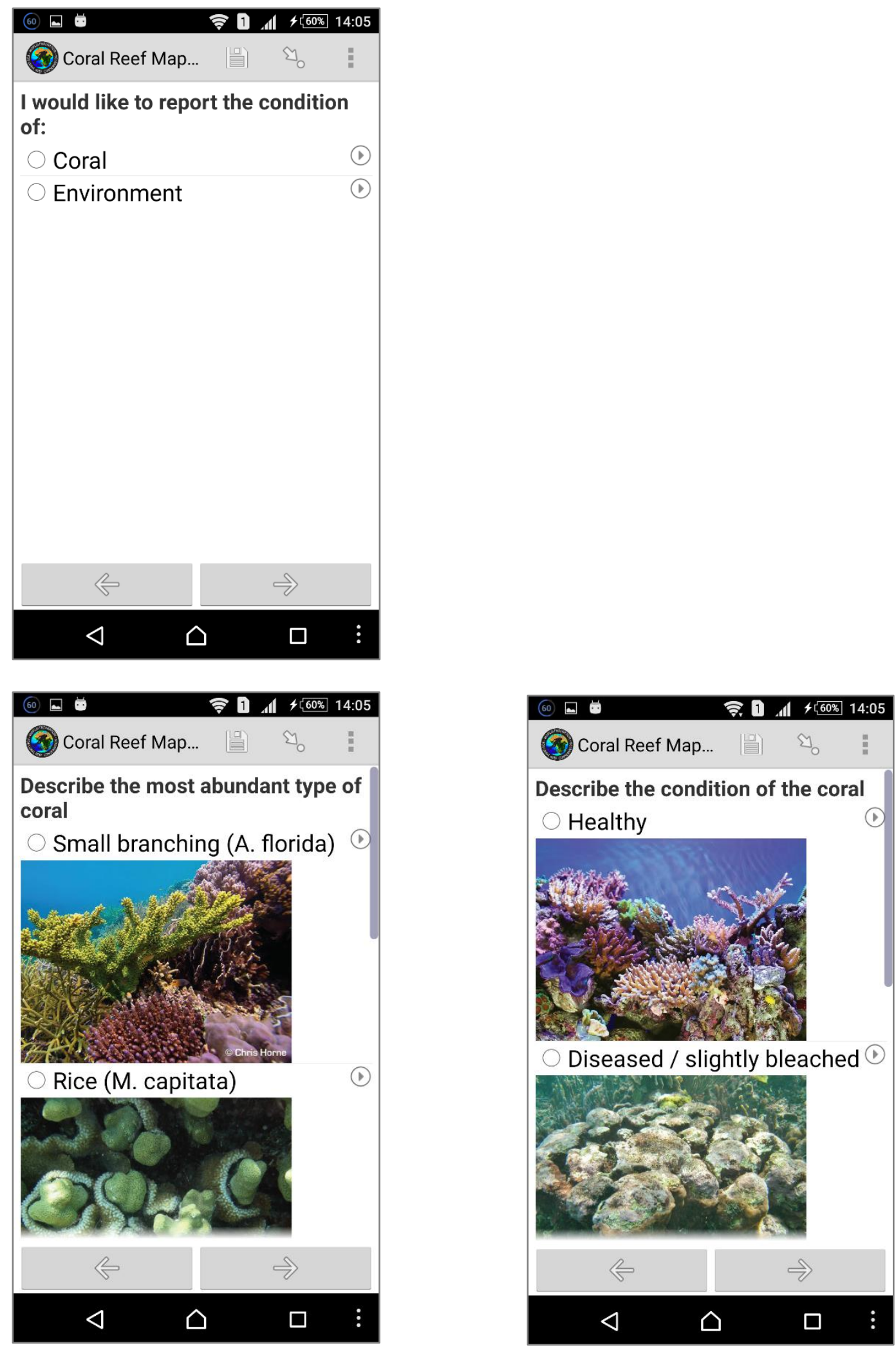

Figure 6-3: Observation type options. 
In the next view, the user selects one or more environmental conditions that they have observed, and that have caused them concern. In the next view shown in Figure 6-4, the user selects one or more of the habitats that they saw during their observation (see Figure 6-4).
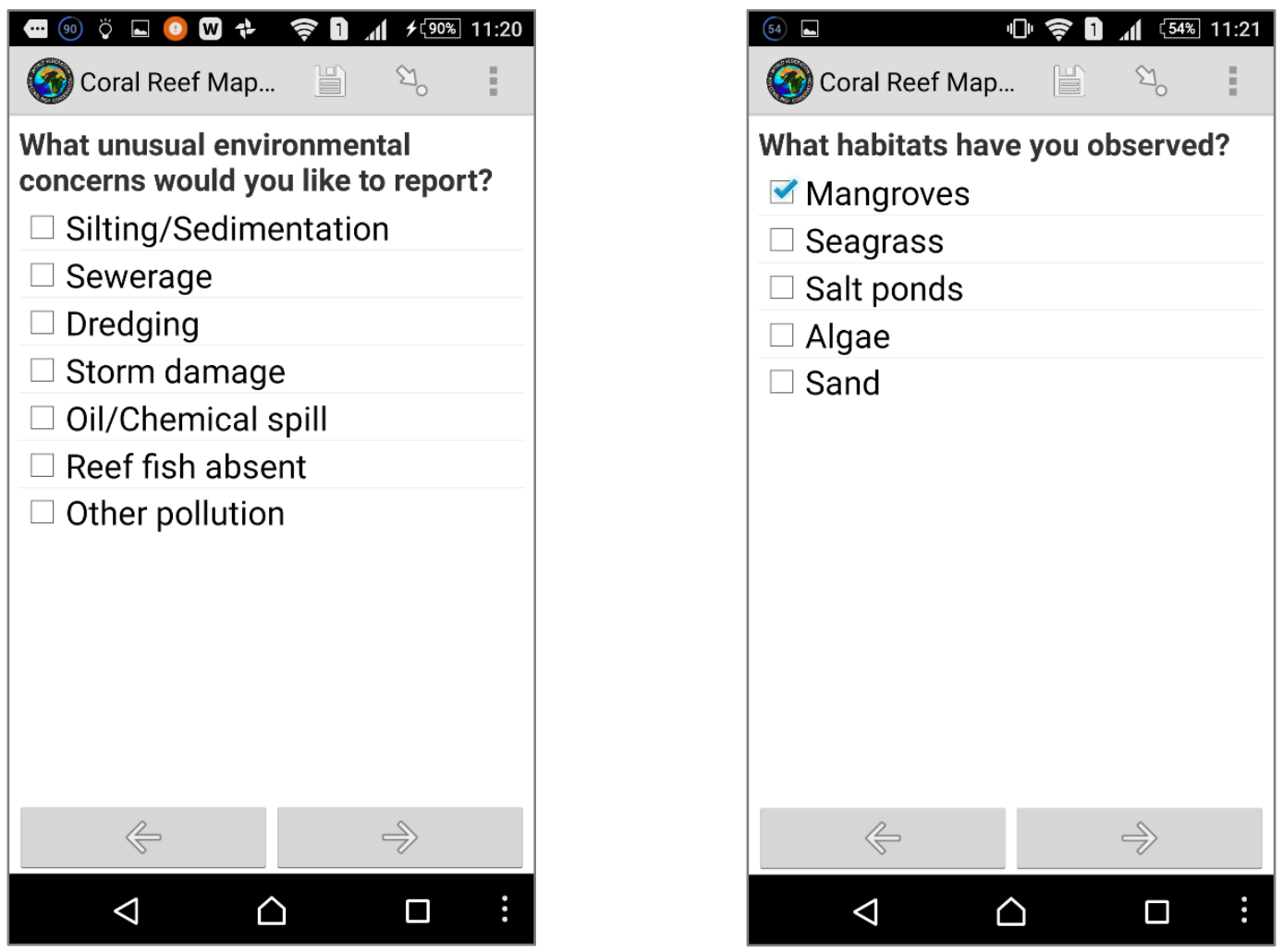

Figure 6-4: Environmental concerns and habitats observed.

Lastly, the user types in any notes that they might have concerning their observation, and submits the data collection form presented in Figure 6-5. If the user is offline, this form will be stored on their device until it connects to the Internet, upon which the observation will be published to the Google App Engine cloud storage. 

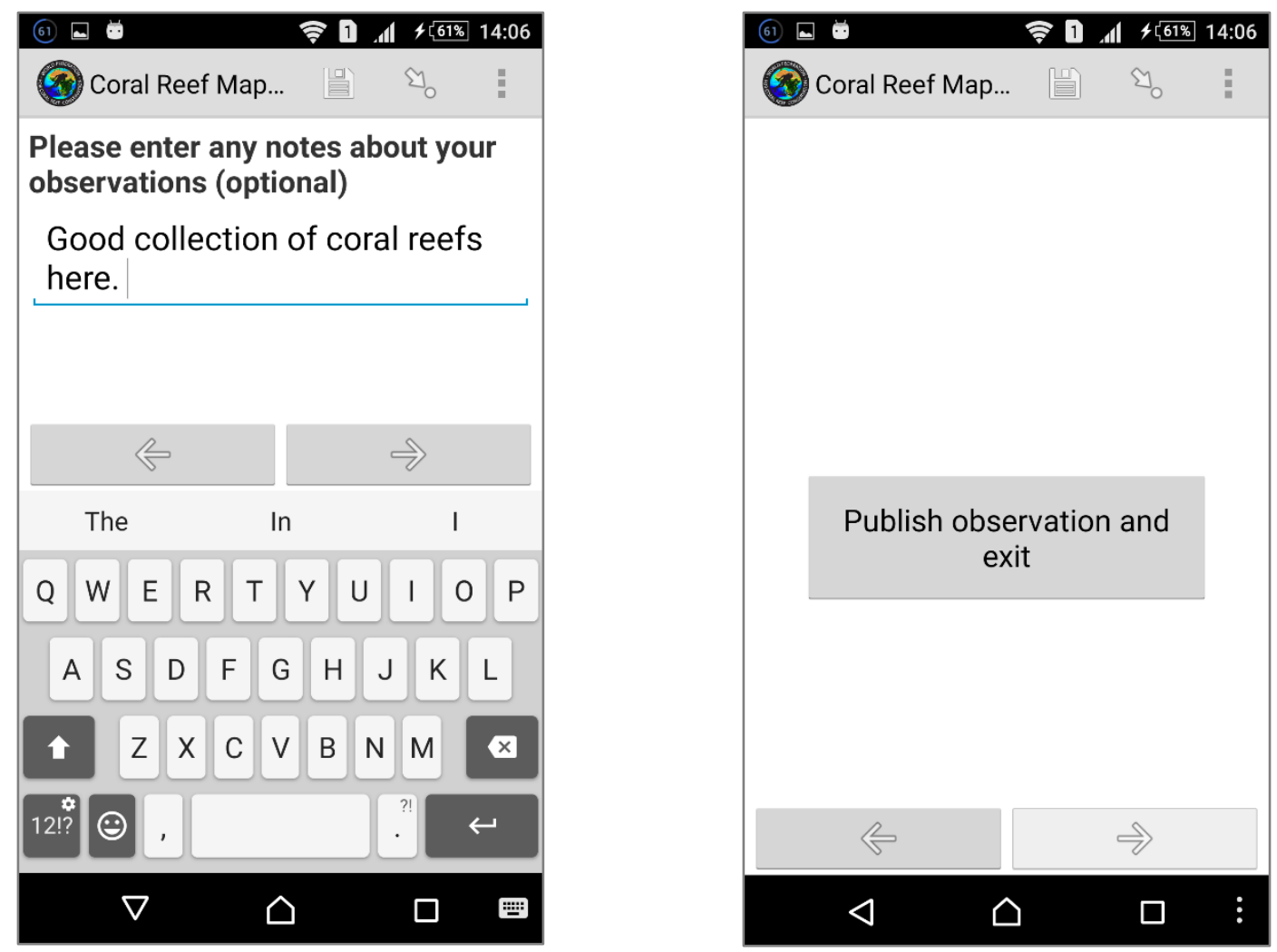

Figure 6-5: Observation notes and submission view.

\subsection{Use Case 2: Cloud Storage Environment}

As soon as the citizen scientist submits their observation to the cloud storage environment, the data administrator receives an email notification with the subject line "PLEASE REVIEW Coral Reef Observation." The content of the email is a link to a Google form containing an individual record to be reviewed as shown in Figure 6-6. Reviewing this form enables the data administrator to perform a quality control check, and opt to approve or reject the observation. When the administrator clicks "Yes" to approve, these data immediately become publicly available in the web mapping application. 


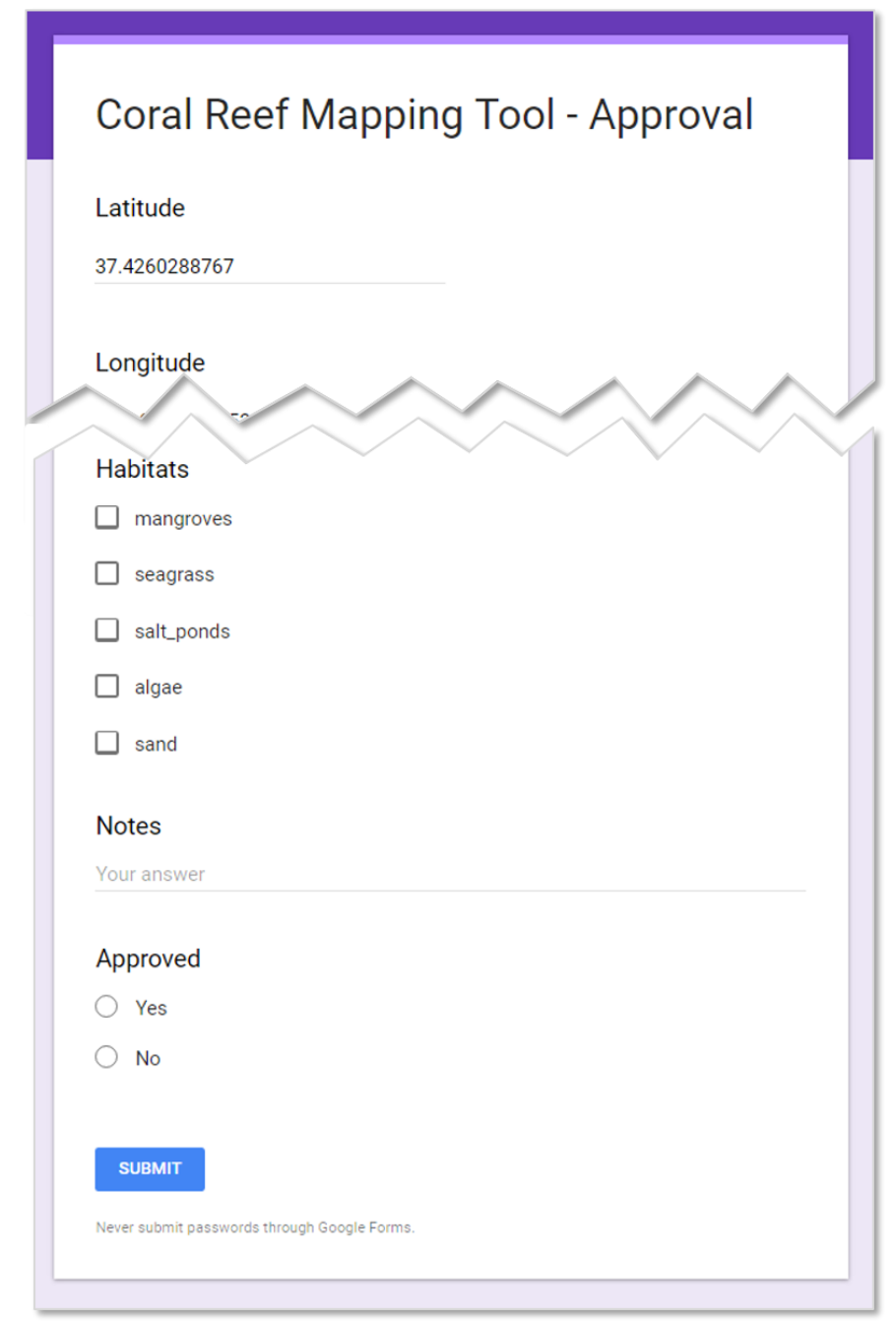

Figure 6-6: Data quality control approval form.

The data administrator can view all the published records (approved and unapproved) from within the ODK Aggregate web application (Figure 6-7). This application has a simple interface that users can use to manage their data without having to manage the underlying data relationships. While the interface does not provide an option to edit the data, submitted observations can also be deleted here, with a cascading effect to the web mapping application. 


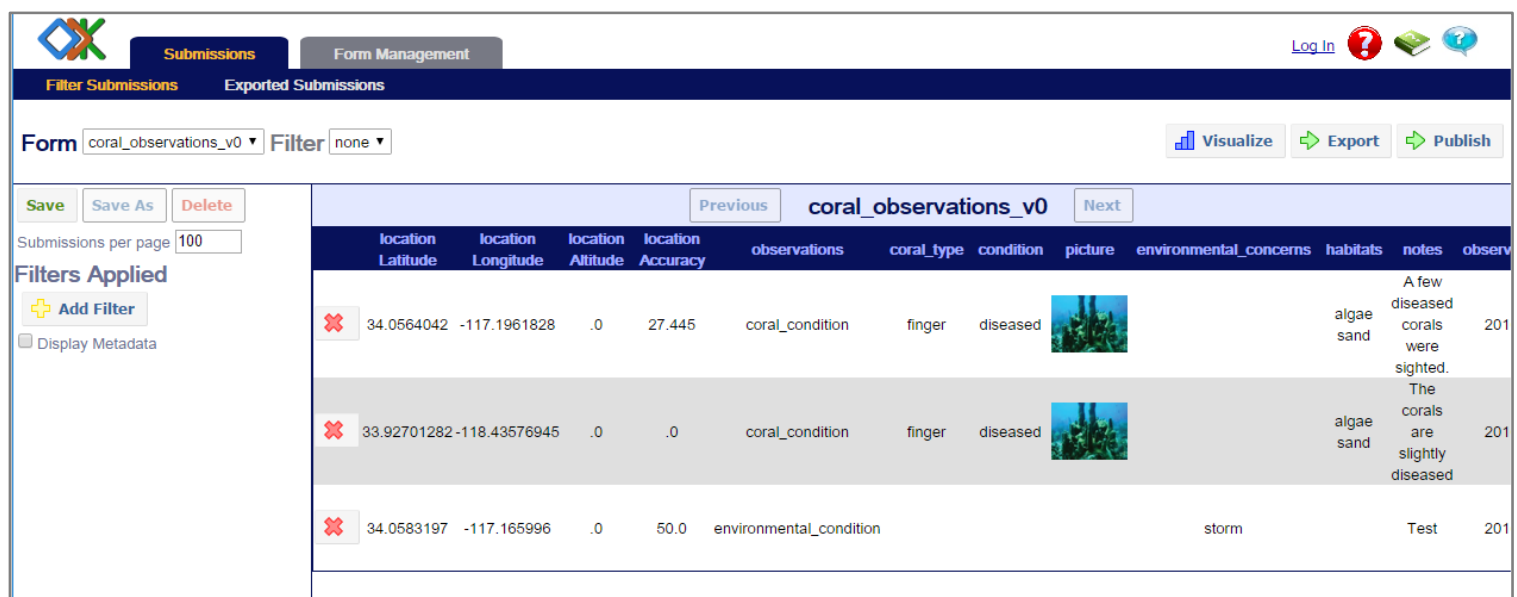

Figure 6-7: Web application interface for managing data submissions.

\subsection{Use Case 3: Web Mapping Application}

The web mapping application provides a simple interface allowing a user to view the observations that have been published by other citizen scientists. The application may be accessed from desktop, tablet, and mobile devices with a consistently optimal viewing experience. The interface has been deliberately kept simple, giving the user basic navigation tools and pop-ups when icons are selected/clicked (Figure 6-8).

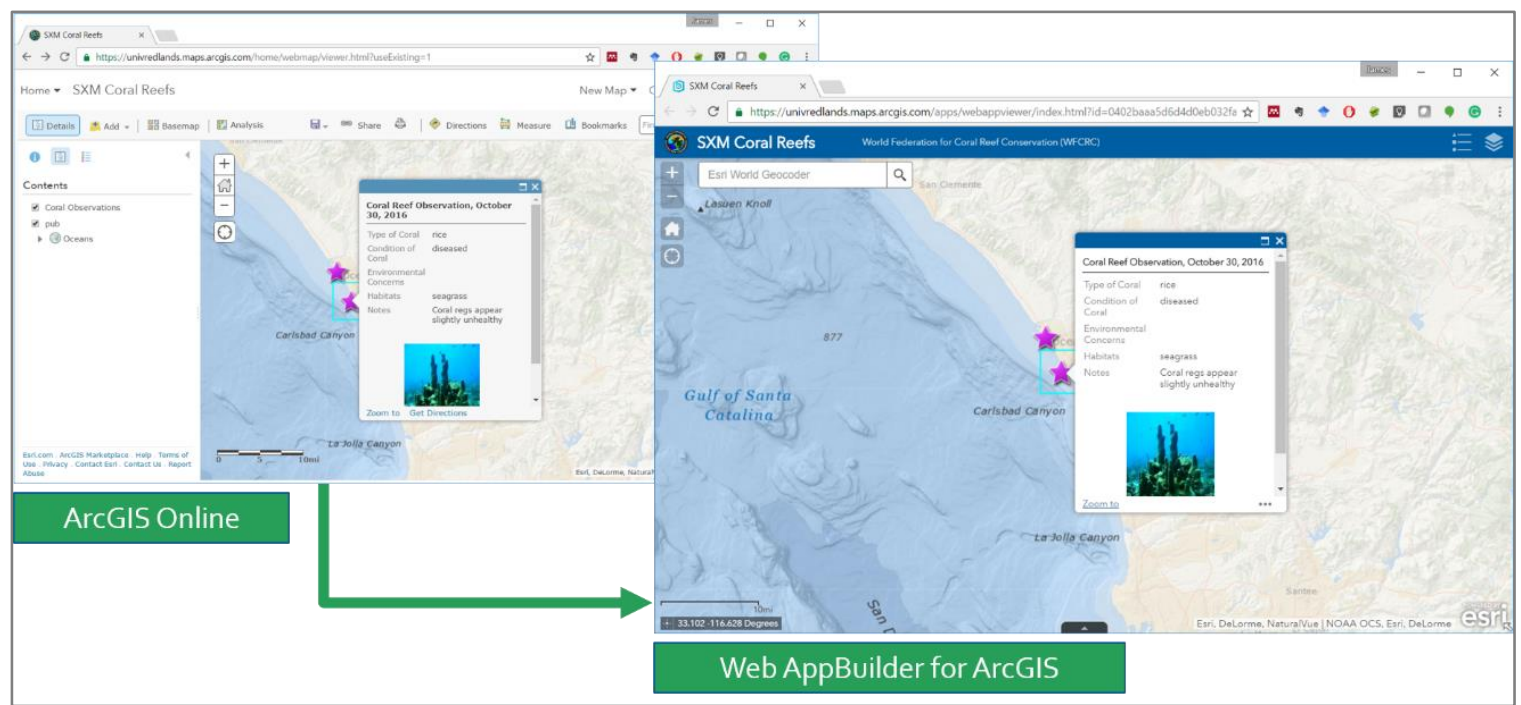

\section{Figure 6-8: Web mapping application.}

\subsection{Summary}

In this chapter, the usefulness of the application as a citizen science tool was clearly demonstrated, through the three use cases discussed in Sections 6.1, 6.2, and 6.3. They captured the complete workflow from field data collection to the availability of the data through a web application. The subsequent, and final, chapter of this report addresses 
some of the challenges that were experienced and suggests some future improvements that can be made. 


\section{Chapter 7 - Conclusions and Future Work}

The client was the World Federation for Coral Reef Conservation, a non-profit organization focused on collecting and publishing coral reef information, and developing strategies for mitigating threats. This project sought to provide a solution to help the client engage citizen scientists, including recreational divers and the local community, to collect information and increase awareness about coral reefs. The solution consisted of a mobile application, a cloud storage environment, and a web mapping application.

The mobile application was developed for Android OS based on Open Data Kit (ODK), a set of open source software development tools. A data collection form based on the XForms specification was designed to inform the mobile data collection exercise. The mobile application was developed to support both online and offline data collection, and to enable the user to record their coral reef and environment observations using a series of views on their Android device.

The cloud storage environment was based on a web application deployed in the Google App Engine cloud storage environment. A quality control process was designed into the cloud storage environment, based on Google Spreadsheets and Google Forms and supported by two Google Drive add-ons: FormMule and CopyDown. Update triggers were used to notify the data administrator of any updates to the database, while Forms enabled the administrator to review and approve published observations.

The web application was configured based on Esri's Web AppBuilder, a templatebased ArcGIS Online web application solution. The web application was designed to enable users in the public domain to view all the published coral reef observations on a map, and in context alongside other data related to coral reef conservation. This was a simple and responsive application that enabled viewing in desktop and mobile environments.

Some of the challenges encountered in this project could not completely be resolved. According to experts, the typical citizen scientist would have difficulty distinguishing between dead, healthy, and diseased coral. It was useful to include pictures in the tool and to have a data review process, but data collected may require more stringent quality assurance and control. Another challenge was that despite the interest by users in using the tool underwater, GPS (and mobile phone) signals only penetrate a few feet underwater.

The project met all the requirements and was very well received by the client, who expects to deploy the tool in the field in early 2017. Further, the tool was presented to the scientific community at the 2016 Esri Ocean Forum, and received much interest. It was viewed as a timely solution to coral reef data collection, not only in St. Maarten, but in other locations of interest.

This project took a first step toward addressing coral reef conservation issues in St. Maarten by providing a tool to enable recreational divers to report on the state of these corals around the island. These observations are expected to contribute towards a Coastal Protection Master Plan for St. Maarten. However, many functionalities and improvements that were suggested and discovered during development could not be implemented in the project's limited time scope. These ideas could be undertaken in future extensions of this project. 
The first option is to improve on the data quality control process. The email notification system could be developed into a configurable application that allows the administrator to set the frequency of notifications to hourly, daily, weekly, and so on. The administrator could also opt to receive the notifications as a summarized email digest that states the number of new records uploaded in the specified reporting period. Further, a privately-accessible administrator application could be developed to map unverified data records, automatically deleting records once reviewed and approved by the administrator. Aspects of the quality control process could be automated. For example, if baseline data are available, the mobile application could be configured to automatically match features between available imagery with the user's selection.

Another option to consider in future is to allow users to specify where they are when recording observations. They could be directly above the observation, within a few meters of the observation, or elsewhere. This would provide an additional data quality check that could be compared to the GPS recording.

In the future, this Android mobile application could be ported to other platforms such as iOS and Windows. This would significantly improve its uptake and use. Development targeted Android OS, based on statistics showing that in 2016, 87.6\% of smartphones worldwide were running Android OS (Llamas, Reith, \& Nagamine, 2016).

In conclusion, the coral reef mapping tool has the potential to play a significant role in coral reef conservation, in St. Maarten and around the world. Industry stakeholders have already shown much interest in adopting the tool in various locations. As more people get engaged, the demand for such simple and innovative solutions will hopefully continue to increase among the coastal and marine conservation communities. 


\section{Works Cited}

Apache License, Version 2.0. (2004). Retrieved from

https://www.apache.org/licenses/LICENSE-2.0

Boyer, J. M. (2009). XForms 1.1. Retrieved November 29, 2016, from https://www.w3.org/TR/xforms/

Chivite, I. (2015). Survey123, Collector and GeoForm (a quick comparison). Retrieved October 11, 2016, from

https://geonet.esri.com/groups/survey123/blog/2015/09/04/survey123-collector-andgeoform-a-quick-comparison

Codd, E. F. (1971). Further Normalization of the Data Base Relational Model. San Jose, California.

Connors, J. P., Lei, S., \& Kelly, M. (2012). Citizen Science in the Age of Neogeography: Utilizing Volunteered Geographic Information for Environmental Monitoring. Annals of the Association of American Geographers, 102(6), 1267-1289. http://doi.org/10.1080/00045608.2011.627058

Eyes of the Reef Hawaii. (2016). Eyes of the Reef Hawaii. Retrieved from https://eorhawaii.org/

Formhub. (2016). Retrieved November 29, 2016, from https://formhub.org/

Fu, P. (2015). Getting to Know Web GIS. Redlands, California: ESRI Press.

Gonzalez Rivero, M., \& Hoegh-Guldberg, I. O. (2013). Global Reef Record. The University of Queensland Collection.

Google. (2016). Android Studio [Computer Software]. Retrieved from https://developer.android.com/studio/index.html

Hartung, C., Anokwa, Y., Brunette, W., Lerer, A., Tseng, C., \& Borriello, G. (2010). Open Data Kit: Tools to Build Information Services for Developing Regions. Proceedings of the International Conference on Information and Communication Technologies and Development, 1-11. http://doi.org/10.1145/2369220.2369236

ICRI. (2013). A Call by the membership of the International Coral Reef Initiative (ICRI) - October 2013.

Internet Live Stats. (2016). Number of Internet Users (2016). Retrieved May 4, 2016, from http://www.internetlivestats.com/internet-users/

Khaled bin Sultan Living Oceans Foundation. (2016). Living Oceans Foundation. Retrieved December 10, 2016, from https://www.livingoceansfoundation.org/

King, M. (2012). Managing Marine Mammal Observations Using a Volunteered Geographic Information Approach. (Master's Thesis, University of Redlands). Retrieved from http://inspire.redlands.edu/gis_gradproj/159

Korf, M., \& Oksman, E. (2016). Native, HTML5, or Hybrid: Understanding Your Mobile Application Development Options, 1-7. Retrieved from https://developer.salesforce.com/page/Native,_HTML5,_or_Hybrid:_Understanding _Your_Mobile_Application_Development_Options

Lauren, M. (2016, April). Putting Preservation on the Map: Living Oceans Foundation Restores the World's Oceans with Scientific Research. What's Up Magazine. Retrieved from http://www.whatsupmag.com/2016/04/08/107535/living-oceansfoundation-restores-the-world-s-oceans-with-scientific-research 
Llamas, R., Reith, R., \& Nagamine, K. (2016). Smartphone OS Market Share, 2016 Q2. Retrieved November 20, 2016, from http://www.idc.com/prodserv/smartphone-osmarket-share.jsp

Müller, M. U., Medyckyj-scott, D., Cowie, A., Heuer, T.-H., \& Roudier, P. (2013). Current status and future directions of mobile GIS. SIRC NZ 2013 - GIS and Remote Sensing Research Conference, (Koetsier). Retrieved from https://scholar.google.com/citations?view_op=view_citation\&continue=/scholar\%3 Fhl\%3Den\%26as_sdt\%3D0,5\%26scilib\%3D1\&citilm=1\&citation_for_view=h8sFFUAAAAJ:Tyk-4Ss8FVUC\&hl=en\&oi=p

National Oceanic and Atmospheric Administration. (2015). Pacific Islands Fisheries Science Center. Retrieved from https://www.pifsc.noaa.gov/cred/ecospatial_information.php

National Oceanic and Atmospheric Administration. (2016). NOAA's Coral Reef Information System (CoRIS) - What are Coral Reefs. Retrieved from http://www.coris.noaa.gov/about/what_are/

Nature Foundation St. Maarten. (2007). St. Maarten Marine Park Management Plan 2007. Retrieved March 28, 2016, from http://dcnanature.org/wpcontent/uploads/2012/08/StMaartenMarinePark2007ManagementPlan.pdf

Niantic Labs. (2016). Pokémon GO. Retrieved October 11, 2016, from http://pokemongo.nianticlabs.com/en/

NinjaMock [Computer Software]. (2016). Retrieved from http://ninjamock.com/

Nordling, J. (2015). GeoODK [Computer Software].

Okolloh, O. (2009). Ushahidi, or "testimony": Web 2.0 tools for crowdsourcing crisis information. Participatory Learning and Action. Retrieved from https://books.google.com/books?hl=en\&lr=\&id=jjP2mOpQ_F4C\&oi=fnd\&pg=PA6 $5 \&$ dq=citizen+reporting+tool\&ots=viFbsqgLHZ\&sig=HNcWP9fs56fLlnzmZyq18mHLGs

Open Data Kit: Form Design. (2016). Retrieved November 29, 2016, from https://opendatakit.org/help/form-design/

OpenStreetMap. (2016). OpenStreetMap. Retrieved October 11, 2016, from http://www.openstreetmap.org

Reef Check Foundation. (2014). Reef Check Foundation Annual Report 2014.

Reef Check Foundation. (2016). Reef Check Foundation. Retrieved October 11, 2016, from http://www.reefcheck.org/

Seoane, J. (2012). Benthic habitat mapping at Recife de Fora, Brazil: Imagery and GIS. icrs2012.com. Retrieved from http://www.icrs2012.com/proceedings/manuscripts/ICRS2012_5A_8.pdf

Silvertown, J. (2009). A new dawn for citizen science. Trends in Ecology and Evolution, 24(9), 467-471. http://doi.org/10.1016/j.tree.2009.03.017

Sim, J. P. (2015). Geospatial Equipment Management System. (Master's Thesis, University of Redlands). Retrieved from http://inspire.redlands.edu/gis_gradproj/228

Sint Maarten Government. (2014). Year-end 2014 Outlook 2015 Report. Retrieved March 3, 2016, from http://www.sintmaartengov.org/Policy and Reports/Year-end 2014 - Outlook 2015 Report.pdf

SocialCompare. (2015). Foursquare vs Facebook Places, Google Latitude, Gowalla, Loopt. Retrieved November 10, 2016, from 
http://socialcompare.com/en/comparison/location-based-online-services-foursquarefacebook-places-latitude-gowalla-loopt

Statistica. (2016). Smartphone Users Worldwide 2014-2019. Retrieved May 4, 2016, from http://www.statista.com/statistics/330695/number-of-smartphone-usersworldwide/

The Nature Foundation. (2011). Simpson Bay Lagoon Ecological Important Area Monitoring. Retrieved March 3, 2016, from http://www.spawpalisting.org/uploads/files/cb0280b9c3e9f72dabb6176fa7e3df0a64c859e9.pdf

Wilkinson, C., Souter, D., \& Network, G. (2008). Status of Caribbean coral reefs after bleaching and hurricanes in 2005. Retrieved from ftp://152.19.240.127/pub/marine/brunoj/Bleaching papers for NCEAS 3/Caribbean_Status_Report_2005.pdf 

Appendix A. Mobile Application Wireframes 

Frame 1

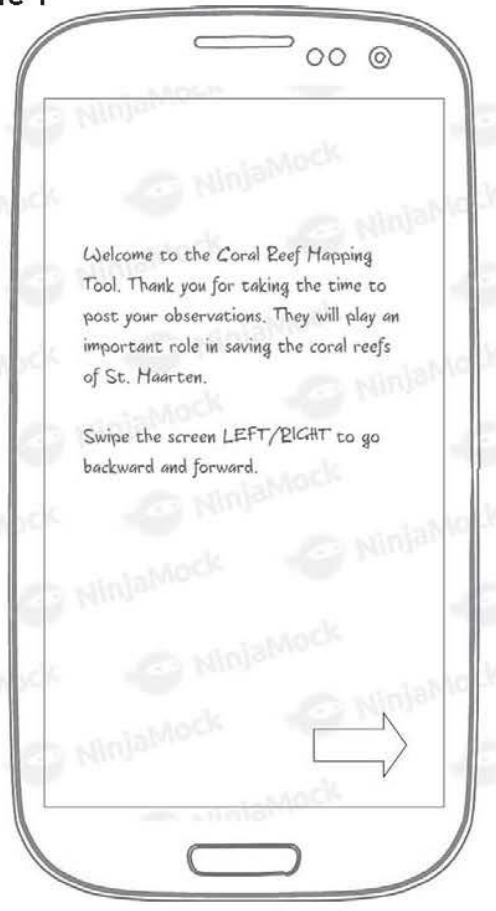

Frame 3

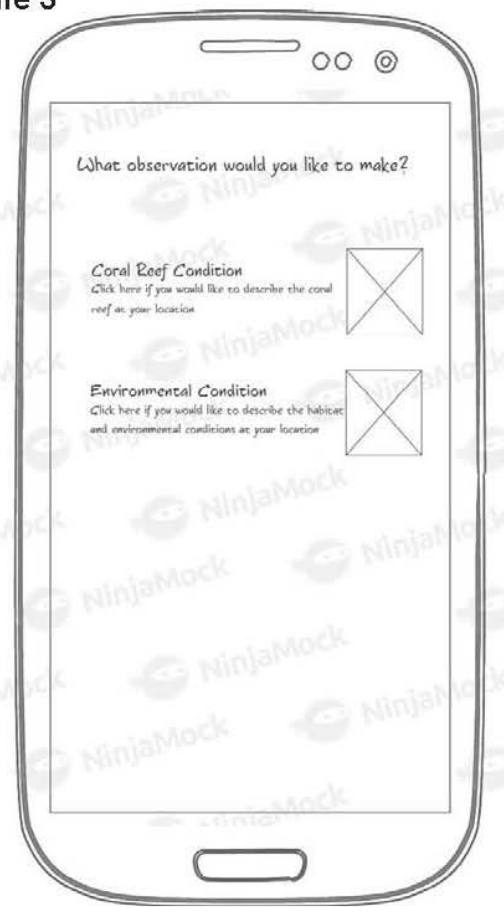

Frame 2

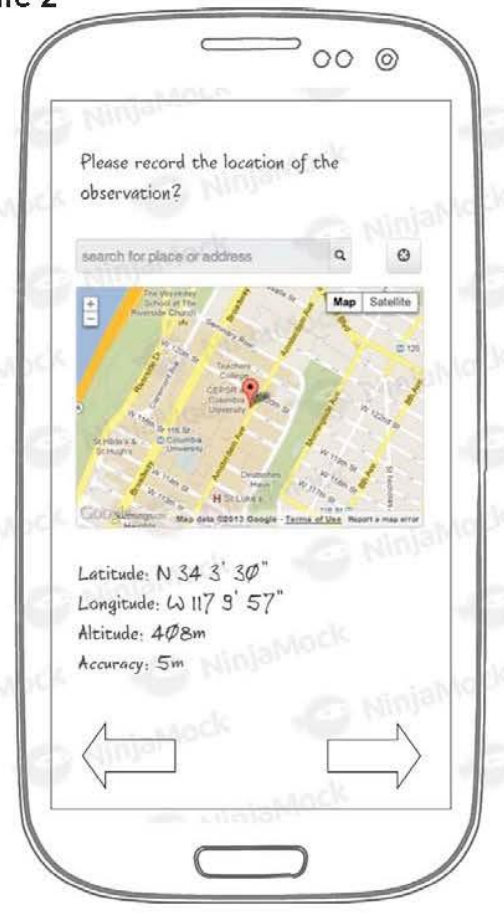

Frame 4

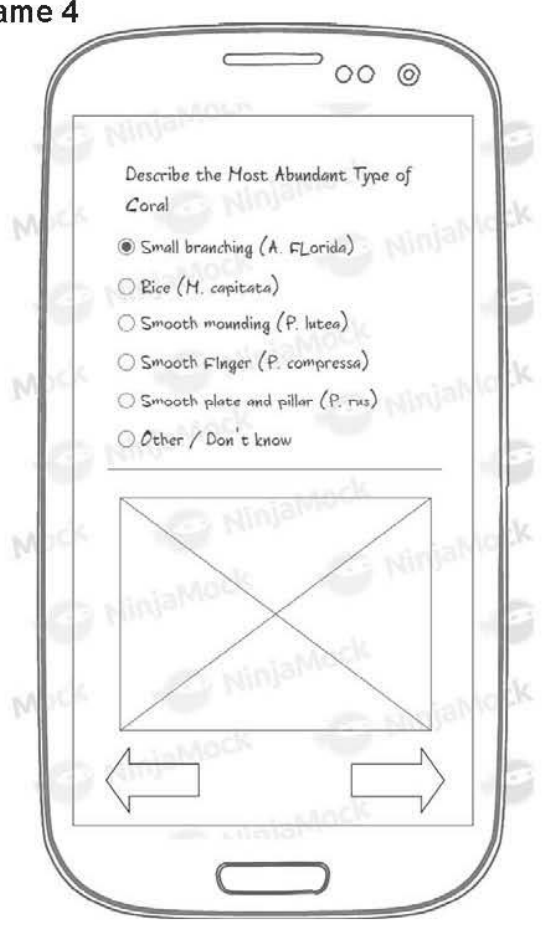


Frame 5

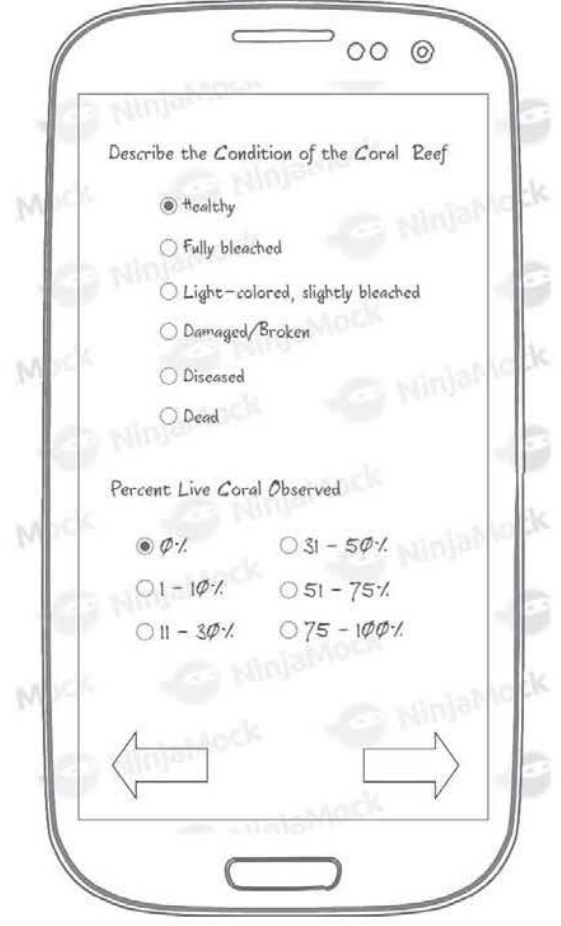

Frame 7

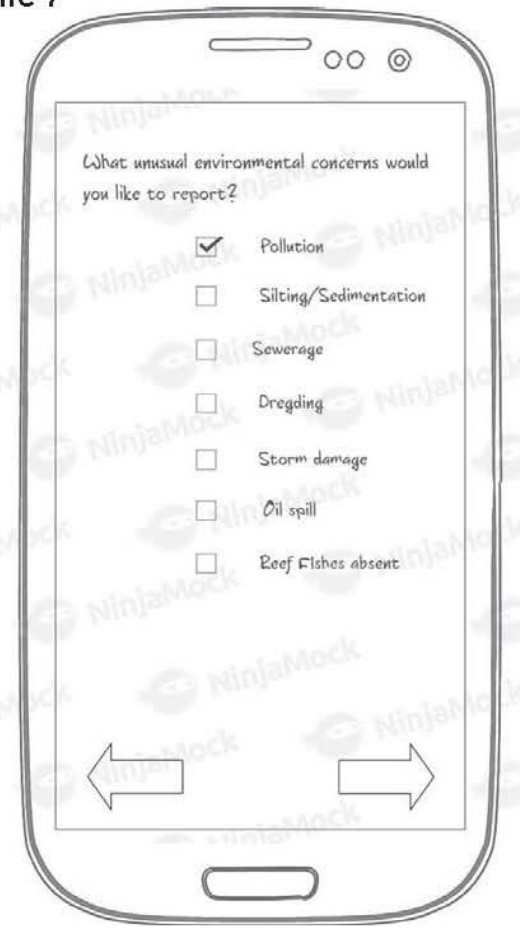

Frame 6

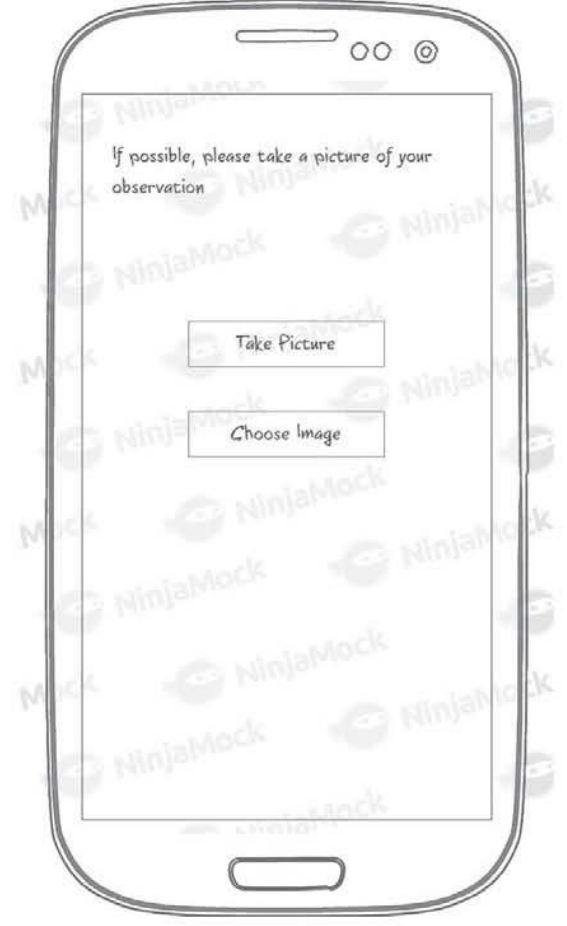

Frame 8

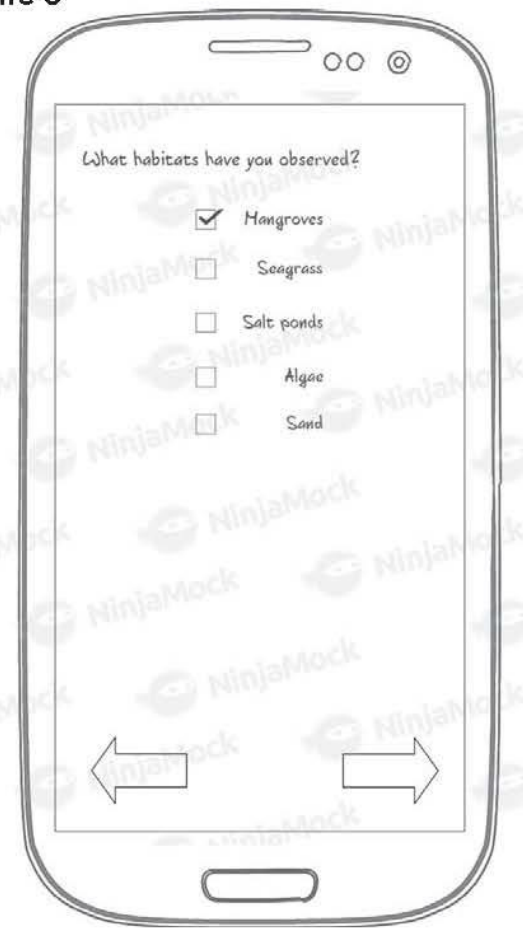




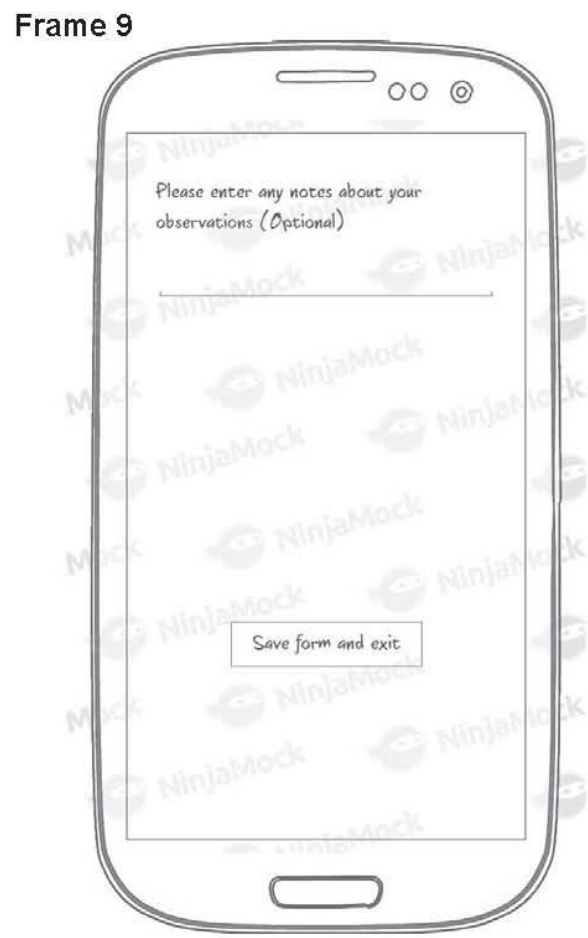



Appendix B. Mobile Application Activities Code 



\section{Data Collection XForm}

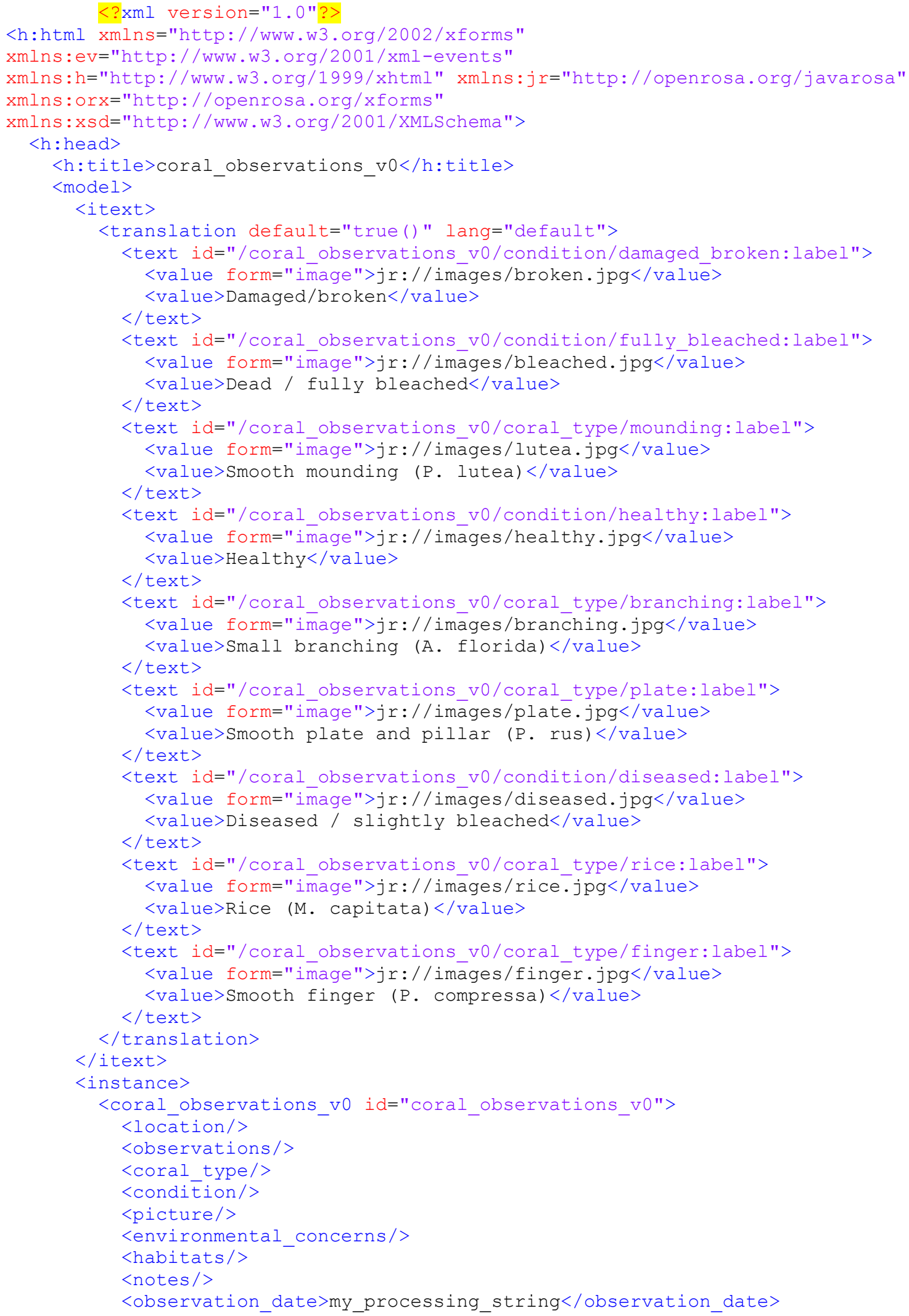




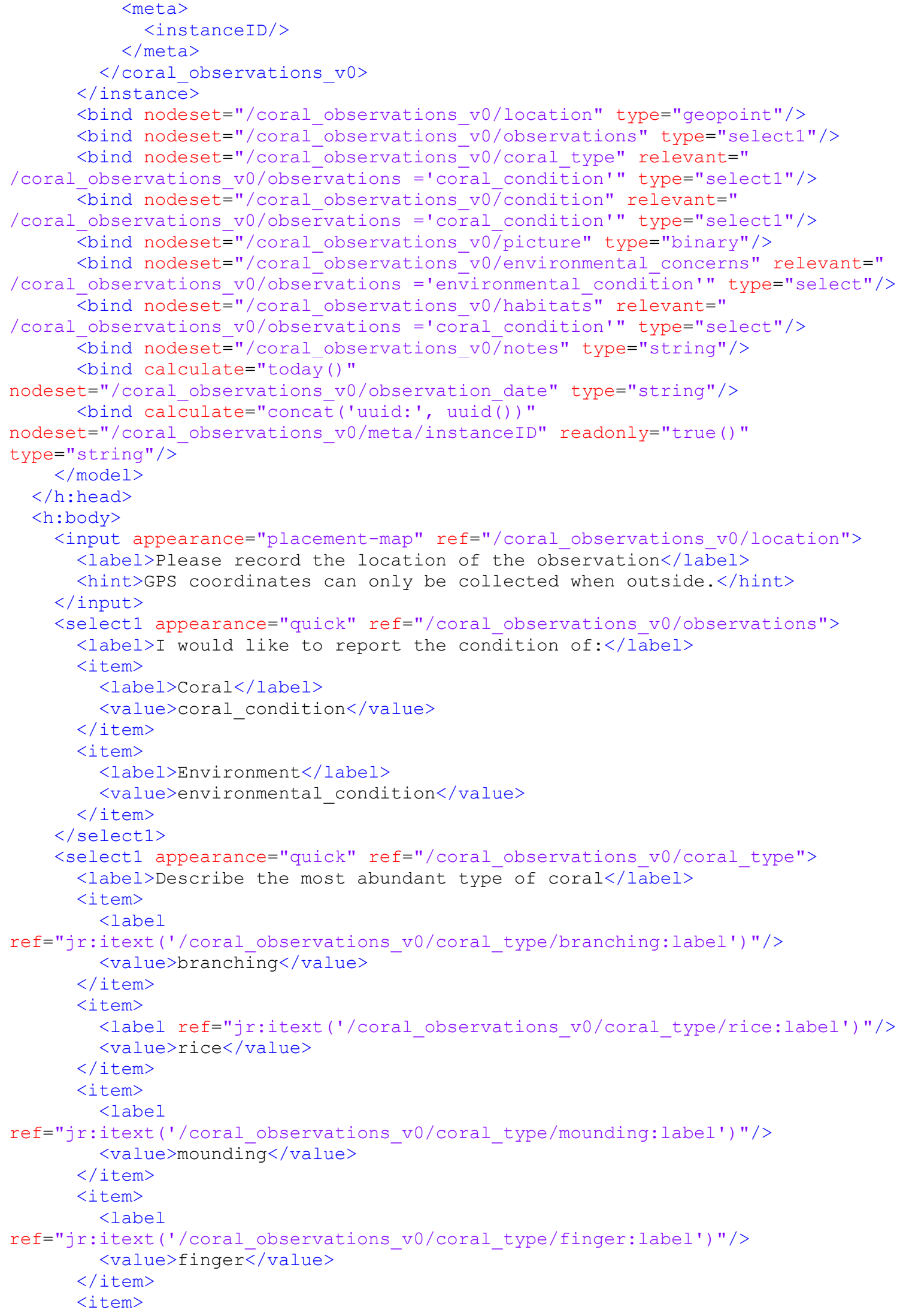




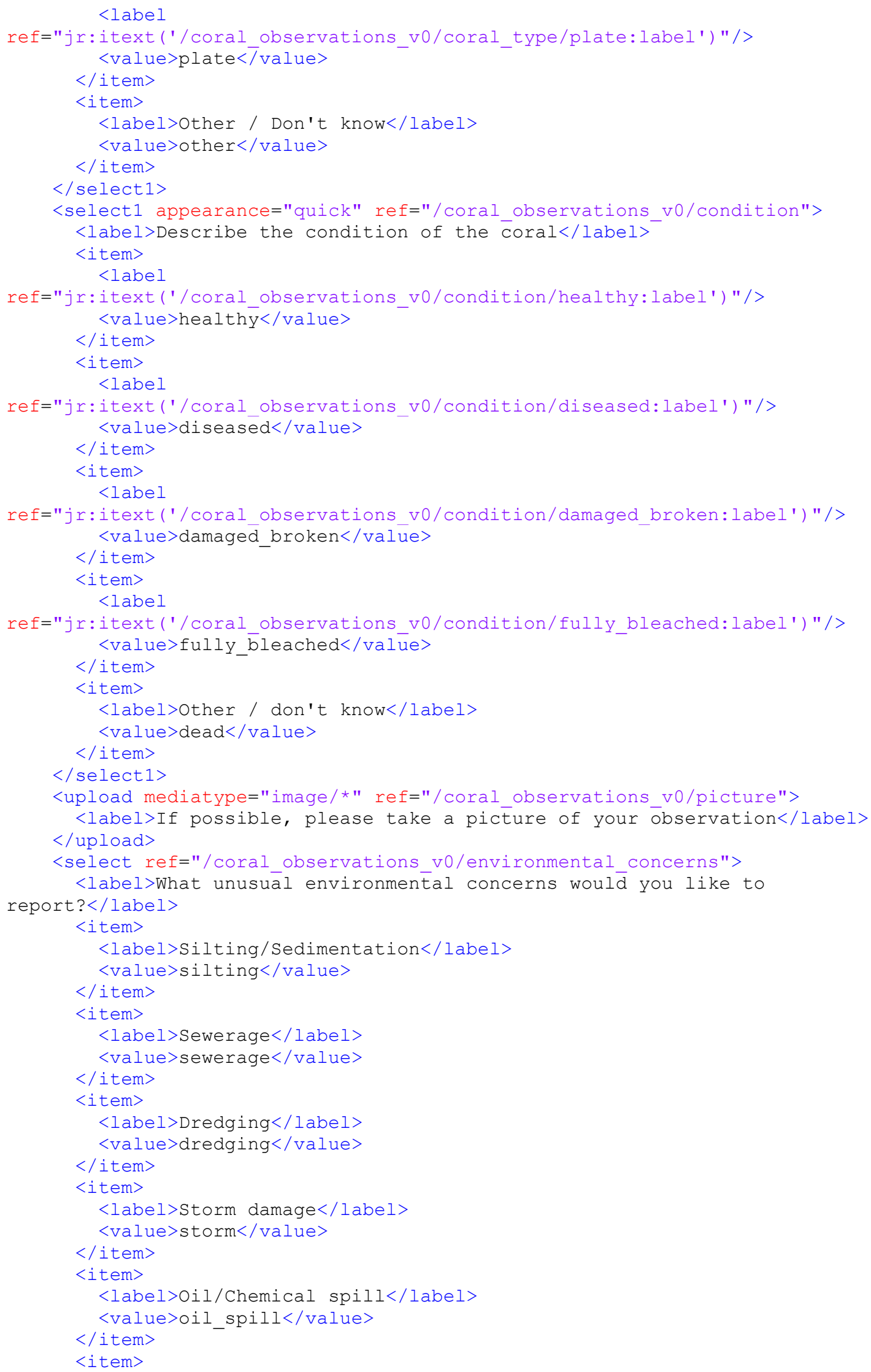




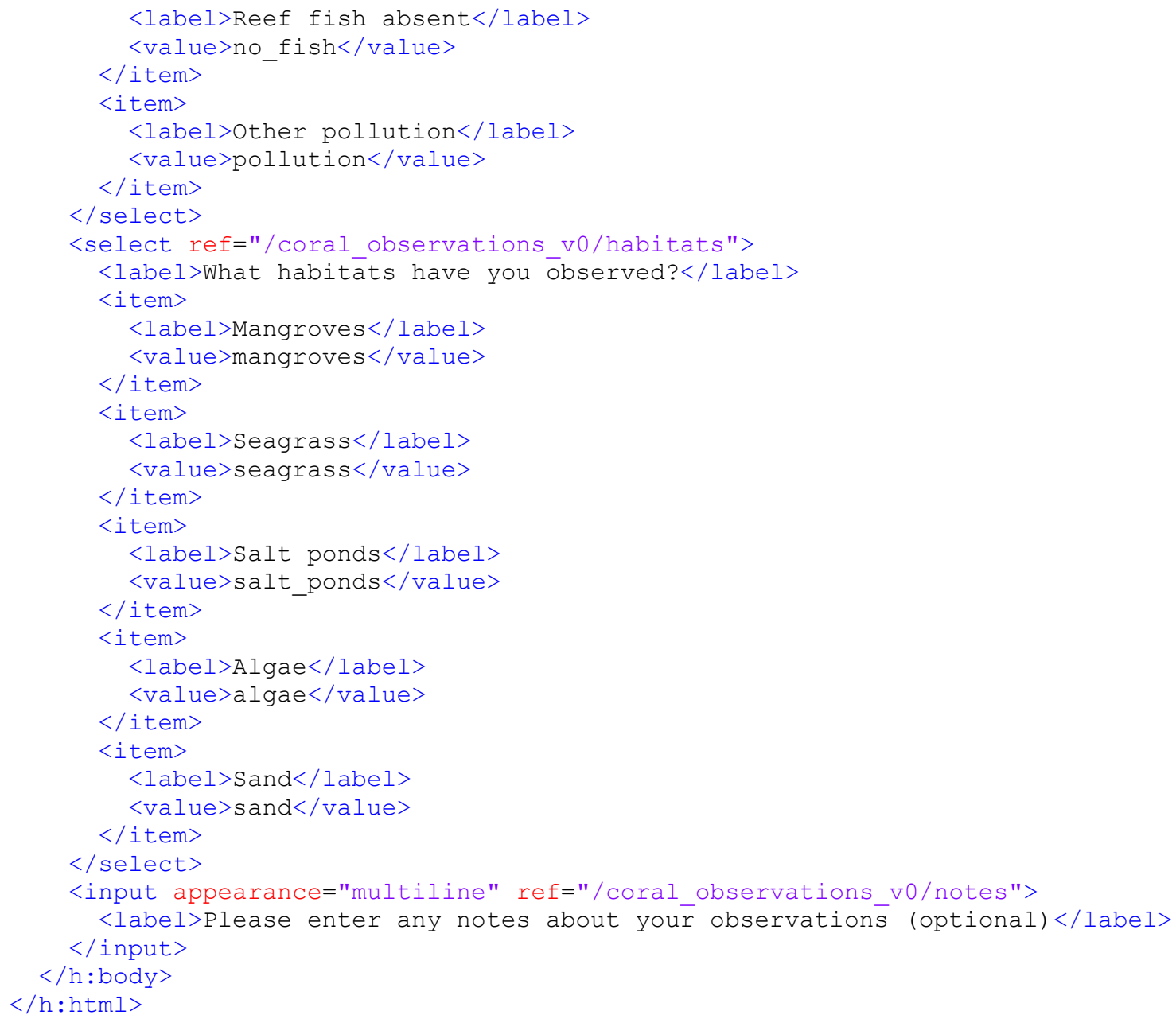

